\title{
Research on the mechanism of the influence of flooding on the killing of empty wells
}

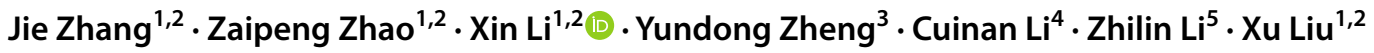

Received: 22 June 2021 / Accepted: 13 August 2021 / Published online: 19 August 2021

(c) The Author(s) 2021

\begin{abstract}
In empty well killing, in order to save the time and cost of killing the well, the dynamic replacement method is often used to kill the well. The main problem of the dynamic replacement method for killing wells is how to avoid terrible working conditions caused by flooding, such as gas carrying fluid, killing fluid being brought to the wellhead. Based on the principle of flooding formation and the basic tenets of flooding correlation experiment and dynamic replacement method, this paper incorporates the kill fluid viscosity, surface tension, droplet diameter, inclination angle, drill pipe joint outer diameter, and drill pipe eccentricity into the calculation range and establishes a new mathematical model suitable for dynamic replacement kill. Based on the calculation results, the influencing factors of flooding are analyzed, and the following conclusions are drawn: the increase of dynamic viscosity, gas density in the well, casing pressure, well angle, the outside diameter of drill pipe, the outer diameter of drill pipe joint, and eccentricity of drill pipe can promote the occurrence of flooding; The increase of surface tension, well-killing fluid density, and casing inner diameter have an obstacle to flooding.
\end{abstract}

Keywords Flooding $\cdot$ Empty well killing $\cdot$ Dynamic replacement method $\cdot$ Gas carrying fluid

\section{Introduction}

During the drilling process, when the liquid column pressure in the wellbore is lower than the formation pressure, the fluid in the formation will invade the wellbore. To avoid a blowout, the process of re-establishing the balance between the wellbore and the formation pressure system in the oil

Jie Zhang

swpivip@163.com

1 State Key Laboratory of Oil and Gas Reservoir Geology and Exploitation, Southwest Petroleum University, Chengdu 610500, Sichuan, People's Republic of China

2 Petroleum Engineering School, Southwest Petroleum University, Chengdu 610500, Sichuan, People's Republic of China

3 Exploration Development, Petrochina Southwest Oil \& Gasfield Company, Chengdu 610066, Sichuan, People's Republic of China

4 Engineering Technology Research Institute, Petrochina Southwest Oil \& Gasfield Company, Guanghan 618300, Sichuan, People's Republic of China

5 Drilling \& Production Engineering Technology Research Institute, Petrochina Chuanqing Drilling Engineering Co., Ltd, Guanghan 618300, Sichuan, People's Republic of China and gas well is the well killing. Control risks have become increasingly prominent with the increase in narrow safety density windows and high-pressure oil and gas layers. Conventional well killing methods are challenging to meet the requirements of well-control, and the demand for research on unconventional well-killing methods is becoming more and more urgent (Li et al. 2013).

Empty well killing is an unconventional method of well killing. After the formation fluid intrudes into the wellbore (this paper mainly studies the gas invasion), the drilling fluid in the well will be blown out and even cause serious accidents, if it is not handled properly. However, the premise of the conventional well killing method is to shut in the well, the drilling tools in the wellbore are at the bottom of the well, and the circulation of killing fluid can be realized. In the process of well killing, the bottom hole pressure is always slightly higher than the formation pressure (Gong et al. 2012). For special situations such as blowout of drilling fluid in the wellbore, no drilling tool in the well or blockage of the drilling tool, and difficulty to remove the plugging, conventional well-killing methods cannot be used to deal with it.

Because of the practical difficulties in killing wells, such as the destruction of the kill fluid channel, excessive 
formation pressure, and the highest bearing pressure of the casing, some empty well-killing methods inevitably include high wellhead back pressure, high pump pressure, long killing time, a large amount of killing fluid and so on. In order to save the amount of killing fluid and reduce the dependence of the killing work on the equipment capacity, the replacement method was proposed for the predecessors of the empty well killing. The replacement method kills the well through the circulation mode of liquid injection-shut-inexhaust - shut-in—liquid injection to reduce casing pressure in stages and finally completes the well-killing work to balance formation pressure. However, due to the long fall time of the shut-in fluid to be killed, the replacement method inevitably requires a long kill time. To solve this problem, Ren et al. (2014) proposed the dynamic replacement method to kill (as shown in Fig. 1). The dynamic replacement method uses the operation mode of liquid injection and exhaust at the same time, which greatly reduces the killing time and also reduces the maximum casing pressure during the killing process. In the dynamic displacement method kill, since the injection and exhaust are performed at the same time, the kill fluid enters the well and flows downward under the action of gravity, and the gas in the well flows upward under the effect of the pressure difference at the exhaust port. During this gas-liquid countercurrent contact process, it is very likely that the kill fluid will be carried out of the wellbore by gas. This gas-carrying phenomenon is called flooding (Levy 1999).

Flooding refers to the phenomenon of gas-liquid twophase countercurrent contact in the flow channel. When the gas velocity reaches a certain critical value, the gas will carry the liquid to the gas outlet in droplets. In the process of gas-liquid two-phase contact, as long as the gas flow rate reaches the critical flow rate of flooding, flooding will occur. At this time, try to reduce the gas flow rate to lower than the required flow rate of flooding to avoid flooding. The schematic diagram of flooding is shown in Fig. 2.

When the liquid droplet is carried above the wellbore, the corresponding gas flow rate is greater than the gas flow rate at which the liquid film is observed to be broken, and the liquid droplet breaks through the liquid film. There are two reasons for flooding (Vijayan et al. 2000): (1) The gas flow near the gas outlet has the effect of transporting the liquid; (2) The liquid film is destroyed during the countercurrent contact with the high-speed gas flow, resulting in droplets. As the flow rate increases, the damage to the liquid film intensifies, and the liquid droplets produced after the liquid film is destroyed are carried out of the wellbore by gas in large quantities. As the gas velocity increases, the disturbance in the liquid film also intensifies. The disruption of the
Fig. 1 Schematic diagram of well killing by dynamic displacement method

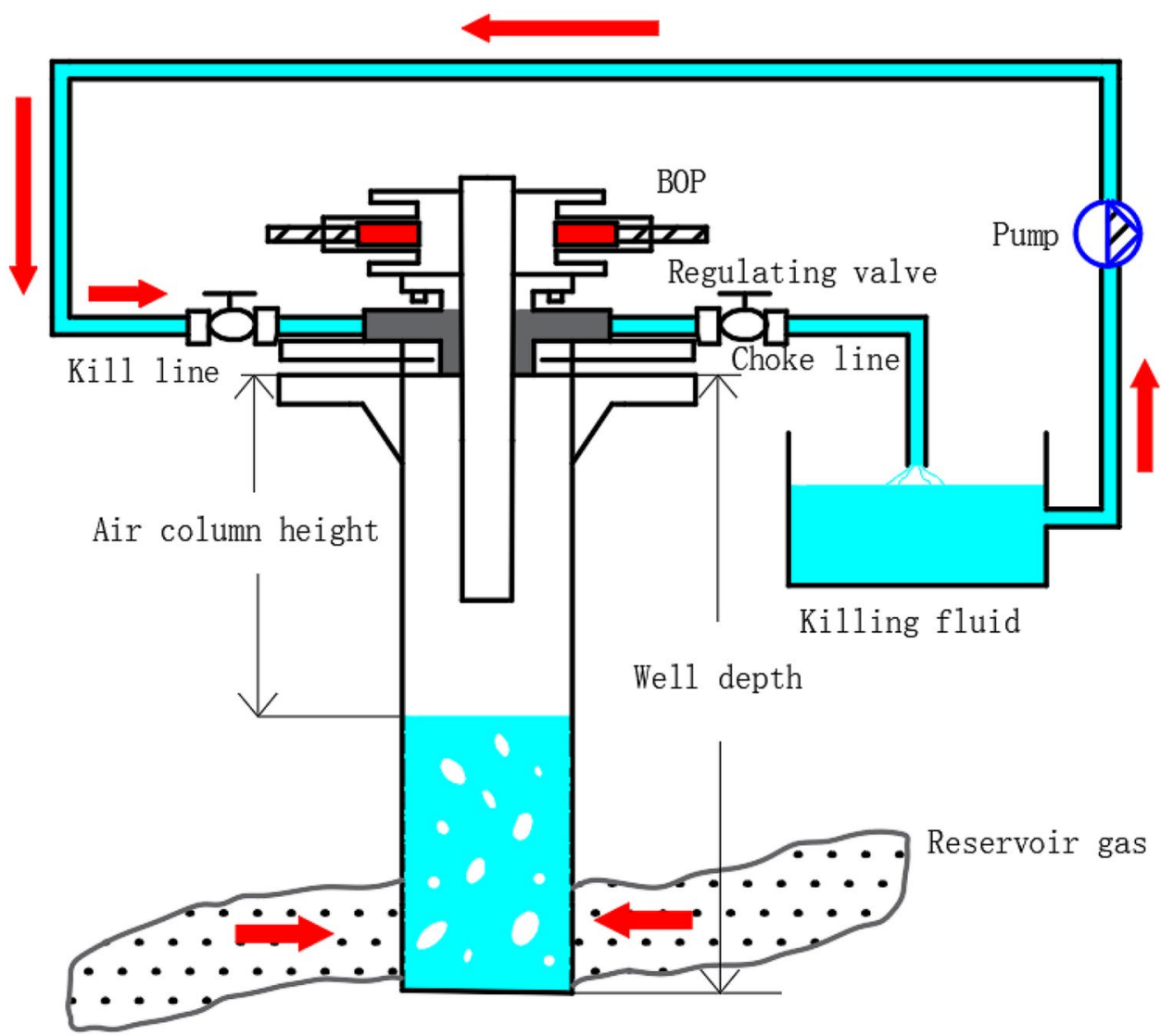


Fig. 2 Schematic diagram of vertical well flooding

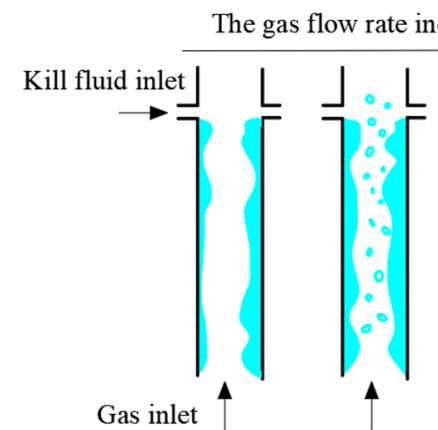

(a)

(b)

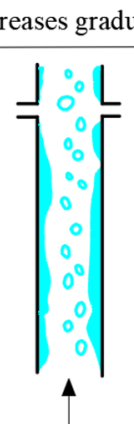

(c)

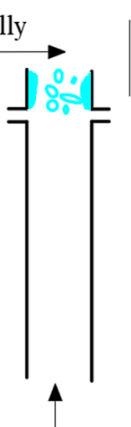

(d)

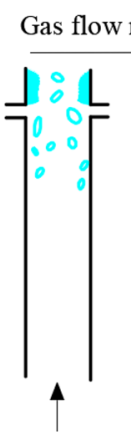

(e)

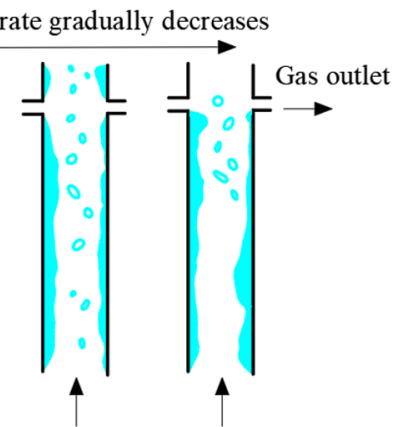

(f)

(g)

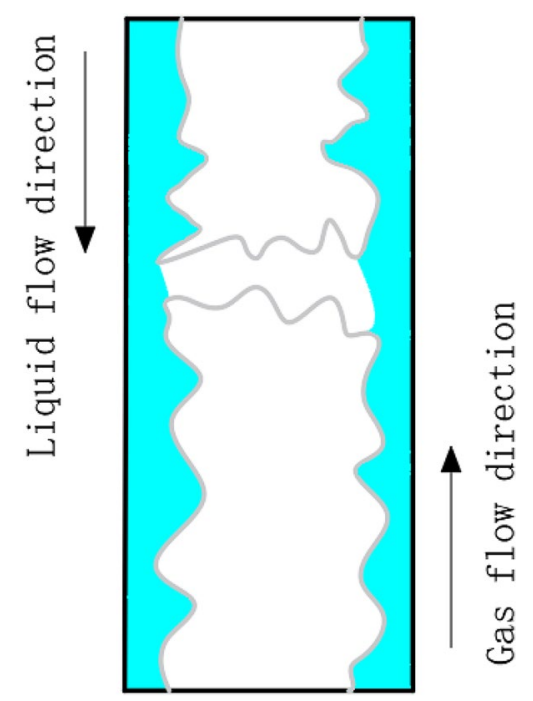

Fig. 3 Schematic diagram of liquid film bridging

liquid film will cause the fluctuation of the liquid film. When the amplitude of the fluctuation reaches a certain value, a bridge of the liquid film is formed, and the gas flow will bring the liquid out, as shown in Fig. 3.

Taitel et al. (1980) believed that in the gas-liquid twophase flow when the average gas content reaches 0.25 , the bubbly flow will transform to the slug flow, and pointed out that the gas content is an important reason for the flow pattern conversion. Andersen and Wurtz (1981) believe that the outer wall of the inner tube of the annulus tube and the inner wall of the outer tube has a layer of liquid film, and the gas core containing tiny droplets occupies the annular space between the two layers of the liquid film. Slightly thicker than the inner tube liquid film. When Sadatomi et al. (1982) studied the two-phase flow in several non-circular pipes, the gas-liquid two-phase flow in the annulus tube was roughly divided into three types: bubbly flow, slug flow, and annular flow. Caetano et al. (1992) and Kelessidis et al. (1989) carried out further research on the gas-liquid two-phase flow pattern in a more extensive range of flow velocity. The gas-liquid two-phase flow pattern in the annulus is further divided into a bubbly flow, dispersed bubbly flow, slug flow, foamy flow, and annular flow. Hasan et al. (1992) believes that for the conversion of slug flow and foamy flow, Brauner's (1986) tube conversion criterion can be applied; that is, when the gas content of the liquid plug part after Taylor bubble exceeds $52 \%$, the slug flow is converted to foamy flow. Grace (1994) proposed the momentum kill method, which is a killing method based on the principle of fluid dynamics. The basic principle is that according to the law of conservation of momentum, the momentum of the kill fluid at the drill bit (or drill string breaking point) is greater than the momentum of the gas in the well, thereby inhibiting the continued intrusion of gas in the well and achieving the purpose of killing the well. This method is especially suitable for situations, where the drill bit leaves the bottom of the well or the drill string breaks down when a blowout occurs. Garlos et al. (2001) gave the momentum formula of gas and killing fluid at the drill bit. Flores-Avila et al. (2002) proposed an improvement to the dynamic kill method in response to a blowout in a gas well, where the drill bit is not at the bottom of the hole. They considered the fall of the kill fluid at the drill bit in the airflow below the drill bit and considered the pressure. The fall of well fluid in gas is a complicated aerodynamic and hydrodynamic problem, and the law of the fall of the kill fluid has been studied through experiments, so that the design of the kill pump displacement is more accurate and reasonable. Li et al. (2009) pointed out that the wellbore is a gas-phase empty wellbore at the initial time of an empty well killing. After the high-density kill fluid enters the wellbore, the liquid column is gradually established, and the wellbore annulus evolves into a two-phase transient flow of gas and liquid. As the bottom hole pressure gradually rises, the gas production of the formation gradually decreases. Yang et al. (2013) pointed out that the casing pressure after shut-in is usually high in replacement killing, reaching about $50 \%$ of the casing internal pressure strength of the wellhead section, or about $50 \%$ of the rated pressure-bearing capacity of the wellhead and well control equipment. At this time, it is necessary to take measures to reduce the casing pressure,

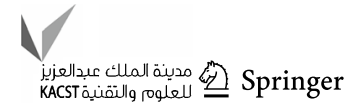


try to prevent formation gas from entering the wellbore or less into the wellbore, and keep the annular liquid column pressure plus the casing pressure greater than the formation pressure. Tao et al. (2014) proposed a special well killing method, mainly to solve the problem that the conventional well killing method cannot be implemented or it is difficult to achieve the ideal killing effect under the conditions of drill tool fracture, puncture leakage, or blockage of the channel in the drill tool. Wei et al. (2017) believe that there are many factors affecting the empty well kill of gas drilling, mainly including wellbore structure, drilling tool assembly, physical formation parameters, kill fluid density, pump displacement, wellhead backpressure, etc. In order to ensure the success of well-killing, it is necessary to carry out optimized combination research on key construction parameters, such as wellhead backpressure, pump displacement, and kill fluid density. Among them, wellhead backpressure is very important to kill wells in gas drilling.

Through the conclusions of previous studies, the following problems are found:

(1) Among the empty well-killing methods, there are the retraction method, dynamic kill method, dynamic kill method, momentum kill method, displacement method, and dynamic displacement method. The flooding phenomenon mainly exists in the dynamic displacement method. Previous studies on the possible flooding of the gas-liquid countercurrent contact process of the dynamic displacement method and the influence of the flooding on the kill parameters are not complete enough. The use of the dynamic displacement method to kill the well must prevent the kill fluid from being ejected with the gas. The purpose of preventing flooding is to solve this problem by studying the critical displacement of flooding.

(2) Most scholars use the two-phase flow model in the calculation of gas intrusion. In order to simplify the measure during the well-killing process, the flow of the annulus mixture is generally simplified to a pure gas column and a pure liquid column flow and analyzed separately. But flooding is a complicated process involving the shearing effect of gas flow on liquid flow, so it is important to consider the interaction between gas and liquid.

(3) In an empty well killing, the geometric parameters and physical parameters of fluid flow in the annulus and wellbore directly impact the occurrence of flooding. Many researchers on flooding often neglect a specific aspect of related parameters for the convenience of calculation. Only when all relevant influencing factors are taken into account can the selection of parameters such as kill fluid displacement play a valuable guiding role.

Therefore, this article carries out the following research to further improve the dynamic displacement kill method.
(1) Study the characteristic parameters of empty well killing. The typical parameters studied include casing pressure, well depth, inclination angle, gas physical parameters in the well, minimum preparation volume of kill fluid, formation pressure, and other original parameters, as well as physical parameters of kill fluid, kill fluid displacement, gas displacement, etc. kill parameters.

(2) Study the influencing factors of liquid flooding in the killing of empty wells. In an empty well-killing, whether flooding occurs is determined by multiple parameters. These parameters are also called floodingrelated parameters. It is necessary to clarify which parameters are included in the flooding-related parameters for the next step of the calculation.

(3) Establish and improve the mathematical model of flooding in air well killing, and calculate with the help of Visual Studio software VB.Net module. The flooding model and the formula of the dynamic displacement method are improved by combining the theory of flooding occurrence and formation, flooding influence parameters, and the characteristic parameters of empty well killing.

(4) Analyze the influence of the influencing factors of flooding on the killing parameters of empty wells. From the perspective of preventing flooding, analyze the influence of flooding factors (Killing fluid density, gas density, killing fluid surface tension, killing dynamic fluid viscosity, casing inner diameter, shut-in casing pressure, well inclination angle, etc.) on the maximum kill fluid displacement, the maximum gas displacement, and the kill time. In the annulus, add the drill pipe outer diameter, the drill pipe joint outer diameter, and the drill pipe eccentricity to analyze their influence on the maximum displacement of the kill fluid, the maximum displacement of the gas, and the kill time.

Through the above research, we summarize the influence law and influence degree of the related flooding parameters on the engineering parameters of empty well killing. It guides selecting engineering parameters for the dynamic replacement method of empty well-killing to prevent flooding during the killing operation.

\section{Flooding calculation model}

During the killing process, the bottom hole pressure must be kept constant. The difference between the hydrostatic column pressure produced by the killing fluid pumped into the well, and the pressure drop created by the gas self-weight caused by the discharge of the gas should be equal to the casing pressure drop value, namely: 
$\rho_{y} g_{y} h-g\left(\rho_{q 0} h_{q 0}-\rho_{q} h_{q}\right)=P_{y 0}-P_{y}$

where $P_{y}$ is the casing pressure after pumping a particular kill fluid, MPa; $P_{y 0}$ is the shut-in casing pressure when killing the well with dynamic displacement method, MPa; $\rho_{y}$ is the kill fluid density, $\mathrm{g} / \mathrm{cm}^{3} ; \rho_{q 0}$ is the density of the gas in the well at the beginning of the killing, $\mathrm{g} / \mathrm{cm}^{3} ; \rho_{q}$ is the gas density in the well at a certain moment, $\mathrm{g} / \mathrm{cm}^{3} ; h_{y}$ is the height of the liquid column of the kill fluid in the well, $\mathrm{m}$; $h_{q 0}$ is the height of the gas in the well at the beginning of the killing, $\mathrm{m} ; h_{q}$ is the height of the gas in the well at a certain moment, $\mathrm{m} ; g$ is the acceleration of gravity, $9.8 \mathrm{~m} / \mathrm{s}^{2}$.

The height of the liquid column formed by the pumped kill fluid in the well is:

$h_{y}=\frac{Q_{y} t}{A}$

where $Q_{y}$ is the pumping displacement of kill fluid, $\mathrm{m}^{3} / \mathrm{s} ; A$ is the cross-sectional area of the wellbore, $\mathrm{m}^{2} ; T$ is the kill time, s.

The density of kill fluid is:

$\rho_{y}=\frac{P_{y 0} A}{g V_{q 0}}+\rho_{q 0}$

where $V_{q 0}$ is the gas volume in wellbore, $\mathrm{m}^{3}$.

The density of gas in the well after exhausting is:

$\rho_{q}=\rho_{q 0} \frac{V_{q 0}}{V_{q 0}+\left(Q_{q}-Q_{y}\right) t}$

The height of the gas in the well after exhausting is:

$h_{q}=\frac{V_{q 0}-Q_{y} t}{A}$

Substituting Eqs. (1), (2), (3), and (4) into (5) and deriving both sides with respect to time $t$ :

$\rho_{y} g \frac{Q_{y}}{A}-\rho_{q 0} g h_{q 0} \frac{Q_{q} V_{q 0}}{\left[V_{q 0}+\left(Q_{q}-Q_{y}\right) t\right]^{2}}=-\frac{d P}{d t}$

The gas is compressible. The sum of the volume of the kill fluid pumped into the well in a unit of time to compress the gas and the volume of the gas to expand with the discharge of the gas, should be equal to the change in the gas volume caused by the pressure change in the unit time. The relationship between gas and liquid displacement is obtained by combining the ideal gas state equation:

$Q_{y}-Q_{q}=\frac{Z_{t} T_{t}}{Z_{0} T_{0} P_{y 0}} V_{q} \frac{\mathrm{d} P}{\mathrm{~d} t}$ where $Q_{\mathrm{g}}$ is the discharge gas flow, $\mathrm{m}^{3} / \mathrm{s} ; Z_{t}$ is the compressibility factor of gas in the wellbore at time $t$, dimensionless; $Z_{0}$ is the compressibility factor of the gas in the wellbore at the initial moment, dimensionless; $T_{t}$ the temperature of the gas in the wellbore at time $t, \mathrm{~K} ; T_{0}$ is the temperature of the gas in the wellbore at the initial moment, $\mathrm{K}$.

In the conventional dynamic displacement method kill parameter calculation model, the flooding discrimination formula is the Wallis flooding formula, which is widely used in predicting flooding, but does not consider the effects of viscosity and surface tension. At the same time, the prediction accuracy is deficient in the range of $\operatorname{Re}_{L}<1000$ (Mouza et al. 2005). Another commonly used Kutateladze flooding empirical formula (Kutateladze et al. 1972) considers the effect of surface tension. Still, it does not consider the impact of feature size in the expression, and the accuracy is not high when predicting flooding in a $30 \mathrm{~mm}$ tube. Therefore, Zapke et al. (2000) proposed a new type of liquid flooding empirical correlation based on Froude number and Ohnesorge number, the form of which is:

$F r_{G}^{a}=-m \cdot F r_{L}^{b} \mathrm{Oh}_{L}^{c}+w$

where $F_{\mathrm{r}}$ is the Froude number; $\mathrm{Oh}_{L}$ is the Ohnesorge number; $a, b, c, w$ are constants.

The constants $a, b, c$, and $w$ in Eq. (9) are fitted from experimental data. This correlation is in good agreement with the experimental data of Clift et al. (1966) and Chung et al. (1980). In the actual situation of empty well killing, the existence of the inclination angle makes the borehole trajectory in the usual sense not completely vertical. Therefore, the angle needs to be introduced into it. Considering the influence of the tilt angle on gravity, it is suitable for predicting the critical velocity of flooding in the tilt angle. The Froude number expression considering the tilt angle is:

$\operatorname{Fr}_{G}=\frac{\rho_{g} v_{g}^{2}}{g D\left(\rho_{l}-\rho_{g}\right) \sin \alpha}$

$\mathrm{Fr}_{L}=\frac{\rho_{l} v_{l}^{2}}{g D\left(\rho_{l}-\rho_{g}\right) \sin \alpha}$

where $\rho_{1}$ is the liquid density, $\mathrm{kg} / \mathrm{m}^{3} ; \rho_{\mathrm{g}}$ is the gas density, $\mathrm{kg} /$ $\mathrm{m}^{3} ; v_{1}$ is the liquid flow rate, $\mathrm{m} / \mathrm{s} ; v_{g}$ is the gas flow rate, $\mathrm{m} / \mathrm{s}$; $D$ is the diameter of flow section, $\mathrm{m} ; \alpha$ is the angle between the cylinder axis and the horizontal plane.

The Ohnesorge number package considers the effects of viscosity and surface tension, and its definition is:

$\mathrm{Oh}_{L}=\sqrt{\frac{\eta_{l}^{2}}{\rho_{l} d_{l} \sigma}}$ 
where $\eta_{1}$ is the dynamic fluid viscosity, $\mathrm{N} \mathrm{s} / \mathrm{m}^{2} ; d_{1}$ is the droplet diameter, $\mathrm{m} ; \sigma$ is the surface tension of liquid, $\mathrm{N} / \mathrm{m}$.

According to the dimensionless and fitting of the critical gas-liquid velocity, the Froude number flooding formula is as follows.

$\mathrm{Fr}_{G}^{1 / 4}=-2.61\left(\mathrm{Fr}_{L} \cdot \mathrm{Oh}_{L}\right)^{1 / 4}+0.98$

In an empty well killing, the conditions to prevent flooding are:

$\mathrm{Fr}_{G}^{1 / 4}+2.61\left(\mathrm{Fr}_{L} \cdot \mathrm{Oh}_{L}\right)^{1 / 4} \leq 0.98$

The simultaneous formula of dynamic displacement method kill parameters is rewritten as:

$\left\{\begin{array}{l}\rho_{y} g \frac{Q_{y}}{A}-\rho_{q 0} g h_{q 0} \frac{Q_{q} V_{q 0}}{\left[V_{q 0}+\left(Q_{q}-Q_{y}\right) t\right]^{2}}=-\frac{\mathrm{d} P}{\mathrm{~d} t} \\ Q_{y}-Q_{q}=\frac{Z_{t} T_{t}}{Z_{0} T_{0} P_{y 0}} V_{q} \frac{\mathrm{d} P}{\mathrm{~d} t} \\ F_{G}^{1 / 4}+2.61\left(\mathrm{Fr}_{L} \cdot \mathrm{Oh}_{L}\right)^{1 / 4} \leq 0.98\end{array}\right.$

The change of casing pressure with killing time is:

$P_{t}=P_{a 0}-\rho_{k} g \frac{Q_{k} t}{A}$

where $P_{\mathrm{t}}$ is the Casing pressure at $t, \mathrm{MPa} ; t$ is the kill time of dynamic displacement method, s.

The relationship between the gas and liquid velocities can be obtained by combining the first two formulas as follows:

$\frac{Q_{q}}{Q_{y}}=1-\frac{Z_{t} T_{t}}{Z_{0} T_{0}} \frac{V_{q} g}{Q_{y} P_{y 0}} \frac{\mathrm{d} P}{\mathrm{~d} t}$

The relationship between the gas discharge flow rate and the casing pressure over time is:
$Q_{y}=A v_{1}$

When the dynamic displacement method kills the well, the gas displacement is:

$Q_{q}=\left(1+\frac{Z_{t} T_{t}}{Z_{0} T_{0}} \frac{\rho_{y} g V_{q}}{A P_{y 0}}\right) Q_{y}$

In this paper, the mathematical model adds six fluid flooding factors, namely, the viscosity of the kill fluid, the surface tension, the diameter of the droplet, the inclination angle, the outer diameter of the drill pipe joint, and the eccentricity of the drill pipe.

According to the re-established kill parameter calculation model of the dynamic displacement method kill well, it can be seen that the critical gas-liquid displacement of flooding is mainly affected by three factors. That is, there are three factors affecting flooding. The first aspect is the geometric conditions of the circulation area: well inclination angle, casing inner diameter, drill pipe outer diameter, and drill pipe joint outer diameter; the second aspect is the characteristic parameters of empty well killing: shut-in casing pressure and drill pipe eccentricity; The third aspect is the physical parameters of the fluid: hydrodynamic viscosity, liquid surface tension, gas density in the well, and killing fluid density. In this paper, the first and second aspects are classified as flooding-related engineering parameters, and the third aspect is classified as flooding-related physical property parameters.

\section{Calculation and analysis model verification}

In order to verify the correctness of the established model, the model was compared with the Ramtahal model calculation results, and the verification model was taken from the Ramtahal experimental model: wellhead temperature

$\left[\left(1+\frac{Z_{t} T_{t}}{Z_{0} T_{0}} \frac{\rho_{y} g V_{q}}{A P_{y 0}}\right)^{1 / 2}\left(\frac{\rho_{q}}{g D\left(\rho_{y}-\rho_{q}\right) \sin \alpha}\right)^{1 / 4}+2.61\left(\frac{\rho_{y}}{g D\left(\rho_{y}-\rho_{q}\right) \sin \alpha}\right)^{1 / 4}\left(\frac{v_{l}^{2}}{\rho_{y} D \sigma}\right)^{1 / 8}\right] \eta_{l}^{1 / 2} \leq 0.98$

Furthermore, the maximum pumping speed of the kill fluid in the dynamic displacement method kill is:
$23.85{ }^{\circ} \mathrm{C}$, casing inner diameter $0.152 \mathrm{~m}$, kill fluid density $1000 \mathrm{~kg} / \mathrm{m}^{3}$, gas volume $6.3 \mathrm{~m}^{3}$, the casing pressure is

$v_{l}=\left\{\frac{0.98}{\left(1+\frac{Z_{l} T_{l}}{Z_{0} T_{0} g V_{q}} \frac{\rho_{y 0}}{A P_{y 0}}\right)^{1 / 2}\left(\frac{\rho_{q}}{g D\left(\rho_{y}-\rho_{q}\right) \sin \alpha}\right)^{1 / 4}+2.61\left(\frac{\rho_{y}}{g D\left(\rho_{y}-\rho_{q}\right) \sin \alpha}\right)^{1 / 4}\left(\frac{v_{l}^{2}}{\rho_{y} D \sigma}\right)^{1 / 8}}\right\}^{2}$

The maximum pumping displacement of kill fluid is: 
Table 1 The critical velocity ratio of gas and liquid flooding

\begin{tabular}{|c|c|c|c|}
\hline \multirow{2}{*}{$\begin{array}{l}\text { Model } \\
\text { Casing pressure (MPa) }\end{array}$} & \multirow{2}{*}{$\begin{array}{l}\text { Ramtahal model } \\
\text { Experimental critical gas-liquid } \\
\text { velocity ratio }\end{array}$} & \multicolumn{2}{|l|}{ This model } \\
\hline & & Critical gas-liquid velocity ratio & $\begin{array}{l}\text { Gas-liquid ratio } \\
\text { error with Ram- } \\
\text { tahal }\end{array}$ \\
\hline 3.10 & 2.00 & 2.166 & $8.3 \%$ \\
\hline 4.83 & 1.65 & 1.747 & $5.9 \%$ \\
\hline Change trend of casing pressure rise & $55.8 \%$ increase & $55.8 \%$ increase & \\
\hline Critical speed ratio change trend & $17.5 \%$ reduction & Critical speed ratio change trend & $19.3 \%$ reduction \\
\hline Error Analysis & 0 & Error of this model & $9.3 \%$ \\
\hline
\end{tabular}

3.10 MPa and 4.83 MPa. Under the above conditions, the critical gas-liquid velocity ratio in this paper is shown in Table 1.

As shown in Table 1, when the casing pressure is 3.10 $\mathrm{MPa}$, the critical gas-liquid ratio of flooding is 2.166 , and the percentage error of the critical gas-liquid ratio of Ramtahal flooding is $8.3 \%$. Under the casing pressure of $4.83 \mathrm{MPa}$, the critical gas-liquid ratio of flooding is 1.748 , and the percentage error of the critical gas-liquid ratio of Ramtahal flooding is $5.9 \%$. When the casing pressure increases by $55.8 \%$, the critical gas-liquid ratio of Ramtahal flooding decreases by $17.5 \%$, and the critical gas-liquid ratio of this model flooding decreases by $19.3 \%$, with a percentage error of $9.3 \%$.

It can be seen that the percentage errors of this model are all less than $10 \%$, so this model is scientific and practical. The mistake here is caused by the consideration of the surface tension of the liquid, the dynamic viscosity of the liquid, and the diameter of the droplet during flooding, so it has better practicability than the previous models.

\section{Analysis of factors affecting flooding}

\section{Engineering parameters when casing pressure is $3.10 \mathrm{MPa}, 4.83 \mathrm{MPa}$}

In order to confirm to the engineering reality, the shut-in casing pressure is selected below $5 \mathrm{MPa}$ for calculation in analysis and calculation.

In this section, the shut-in casing pressure is $4.83 \mathrm{MPa}$, the well depth is $347 \mathrm{~m}$, the wellhead temperature is $23.85^{\circ} \mathrm{C}$, the temperature gradient is $0.015^{\circ} \mathrm{C} / \mathrm{m}$, the casing inner diameter is $0.152 \mathrm{~m}$, the drill pipe outer diameter is $0.1016 \mathrm{~m}$, the kill fluid density is $1000 \mathrm{~kg} / \mathrm{m}^{3}$. The gas density is $30 \mathrm{~kg} / \mathrm{m}^{3}$, the surface tension of kill fluid is $0.03 \mathrm{~N} / \mathrm{m}$, the dynamic viscosity of kill fluid is $0.025 \mathrm{~N} \mathrm{~s} / \mathrm{m}^{2}$, and the kill fluid droplet diameter is $10^{-4} \mathrm{~m}$ during flooding for research and analysis.

The pressure in the well is called casing pressure when there is no drill pipe in the well, and it is called annulus casing pressure when there is drill pipe.

As shown in Fig. 4a: (1) When the volume of the well is increased, the maximum pumping displacement of the maturation liquid gradually decreases; (2) When the gas volume in the well is less than $20 \mathrm{~m}^{3}$, the maximum pumping amount of kill fluid decreases faster with the decrease of gas volume. It shows that the gas volume in the well limits the critical displacement of kill fluid, and the smaller the gas volume in the well, the more significant the influence of the increase of gas volume on the critical displacement of kill fluid. Therefore, when the gas volume in the well is small, with the increase of gas volume in the well, the pumping amount of kill fluid should be adjusted to a smaller value in time to avoid flooding in the killing process.

As shown in Fig. 4b: As the volume of gas is increased in the well, the critical displacement of the gas increases. This shows that when the gas volume in the well increases, the constraint of gas critical flow on the maximum gas displacement becomes smaller. This effect is more significant when the gas volume in the well is less than $50 \mathrm{~m}^{3}$. At this time, the gas displacement can be appropriately increased.

As shown in Fig. 5a: The well killing time is directly proportional to the casing pressure in the wellbore (annulus). The greater the casing pressure in the wellbore (annulus), the longer the well killing time. This is because the bottom 
Fig. 4 The change of the maximum displacement of kill fluid and gas with the volume of gas in the well

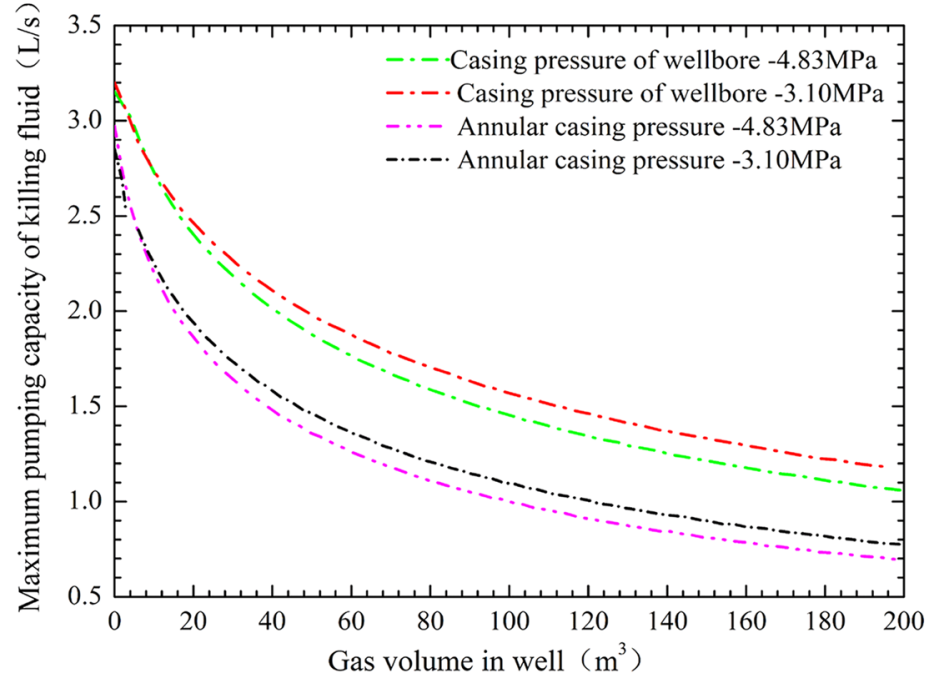

(a) The maximum displacement of kill fluid varies with the volume of gas in the well

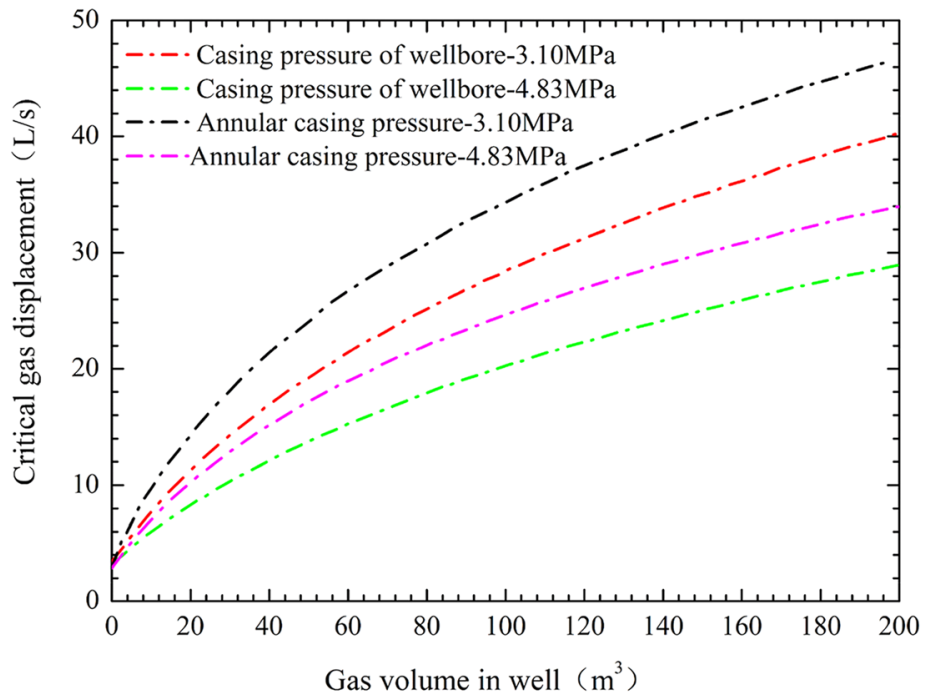

(b) The maximum gas displacement varies with the gas volume in the well hole pressure is always balanced with the formation pressure in the process of dynamic displacement killing. With the continuous injection of kill fluid, the height of the liquid column in the well is increasing. The rising speed of the liquid column is directly proportional to the injection amount of kill fluid. The longer the kill time, the more kill fluid is injected, the higher the liquid column height in the well, and the casing pressure decreases to zero (Table 2).

As shown in Fig. 5b: The gas density is continuously reduced with the increase of the pressure well. This is because, with the increase of well killing time, the casing pressure decreases continuously, resulting in the decrease of gas density in the well.

By comparing the data in Table 3, it can be seen that under the same casing pressure, the critical velocity of killing fluid and gas in the annulus is larger than that in the wellbore. This is because the drill pipe in the annulus acts as a bridge to divert the kill fluid and block the liquid film, which increases the critical velocity of flooding.

However, under the same casing pressure, the critical flow of gas and liquid in the annulus is smaller than the critical flow in the wellbore. This is because there is no drill pipe 


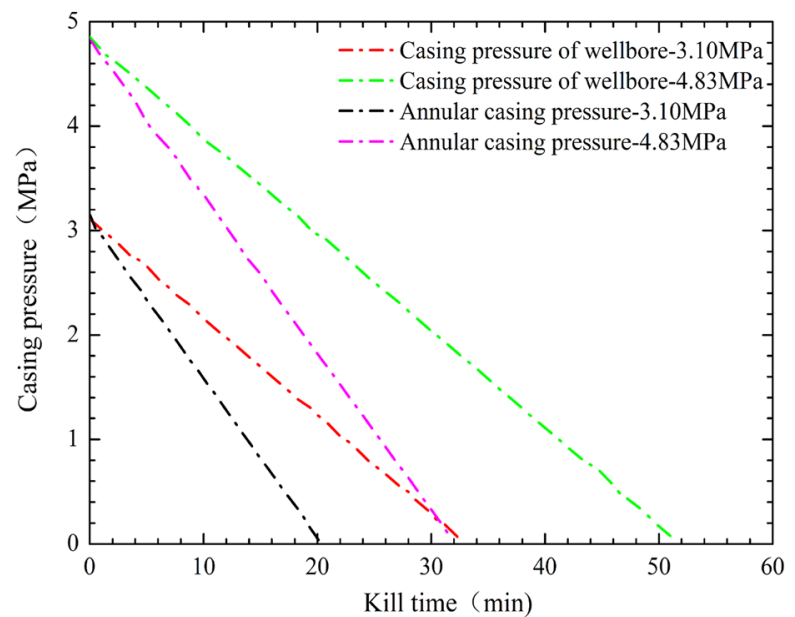

(a) Casing pressure varies with killing time

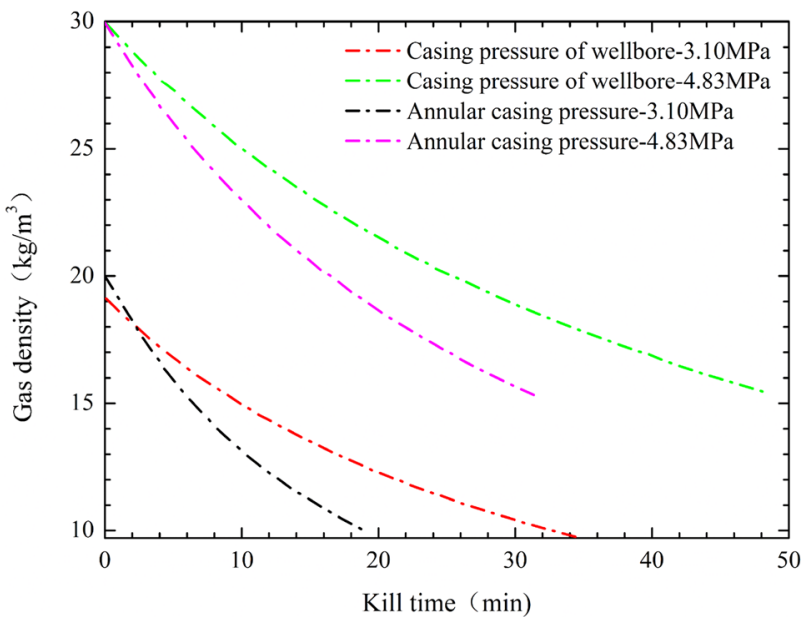

(b) The gas density in the well changes with the killing time

Fig. 5 Casing pressure and gas density in the well change with the killing time

in the wellbore, and the cross-sectional area of gas-liquid countercurrent contact is larger, and the increase in the flow cross-sectional area increases the displacement. The latter has a greater impact than the flooding speed. Therefore, under the same parameters, the critical displacement in the annulus is smaller than the critical displacement in the wellbore.

\section{Analysis of the influence of physical parameters related to flooding}

See Table 4 for the values of basic parameters related to flooding.

The selected kill fluid is low damage kill fluid, and the formula is: $0.6 \% \mathrm{~A}$ (small cation) $+2.0 \% \mathrm{KC} 1+0.5 \% \mathrm{~A} 1 \mathrm{C} 1$ $+0.5 \%$ PEG $400+0.05 \%$ BNP- $10+0.05 \%$ HS- 1 . All additives in
Table 2 Wellbore casing pressure and annulus casing pressure are the basic parameters of well killing at $3.10 \mathrm{MPa}$ and $4.83 \mathrm{MPa}$, respectively

\begin{tabular}{|c|c|c|c|c|}
\hline \multirow[t]{2}{*}{ Basic parameters } & \multicolumn{2}{|c|}{$\begin{array}{l}\text { Wellbore } \\
\text { casing pres- } \\
\text { sure }(\mathrm{MPa})\end{array}$} & \multicolumn{2}{|c|}{$\begin{array}{l}\text { Annular sleeve } \\
\text { pressure }(\mathrm{MPa})\end{array}$} \\
\hline & 3.10 & 4.83 & 3.10 & 4.83 \\
\hline Shut-in casing pressure (MPa) & 3.10 & 4.83 & 3.10 & 4.83 \\
\hline Well deep (m) & 347 & 347 & 347 & 347 \\
\hline Wellhead temperature $\left({ }^{\circ} \mathrm{C}\right)$ & 23.85 & 23.85 & 23.85 & 23.85 \\
\hline Temperature gradient $\left({ }^{\circ} \mathrm{C} / \mathrm{m}\right)$ & 0.015 & 0.015 & 0.015 & 0.015 \\
\hline Inner diameter of casing (m) & 0.152 & 0.152 & 0.152 & 0.152 \\
\hline Drill pipe outer diameter (m) & 1 & 1 & 0.1016 & 0.1016 \\
\hline Kill fluid density $\left(\mathrm{kg} / \mathrm{m}^{3}\right)$ & 1000 & 1000 & 1000 & 1000 \\
\hline Pumping volume of kill fluid $\left(\mathrm{m}^{3}\right)$ & 5 & 5 & 3 & 3 \\
\hline Gas density $\left(\mathrm{kg} / \mathrm{m}^{3}\right)$ & 19.9 & 31.0 & 19.9 & 31 \\
\hline Well angle $\left(^{\circ}\right)$ & 0 & 0 & 0 & 0 \\
\hline Kill fluid surface tension $(\mathrm{N} / \mathrm{m})$ & 0.03 & 0.03 & 0.03 & 0.03 \\
\hline $\begin{array}{l}\text { Dynamic viscosity of kill fluid (N s/ } \\
\mathrm{m}^{2} \text { ) }\end{array}$ & 0.025 & 0.025 & 0.025 & 0.025 \\
\hline
\end{tabular}

Table 3 Calculation results when the wellbore casing pressure and the annulus casing pressure are $3.10 \mathrm{MPa}$ and $4.83 \mathrm{MPa}$, respectively

\begin{tabular}{|c|c|c|}
\hline \multirow[t]{2}{*}{ Basic parameters } & $\begin{array}{l}\text { Wellbore } \\
\text { casing pres- } \\
\text { sure (MPa) }\end{array}$ & $\begin{array}{l}\text { Annular } \\
\text { sleeve pres- } \\
\text { sure (MPa) }\end{array}$ \\
\hline & $3.10 \quad 4.83$ & $3.10 \quad 4.83$ \\
\hline Critical velocity of kill fluid (m/s) & $0.159 \quad 0.158$ & $0.258 \quad 0.256$ \\
\hline Gas critical velocity $(\mathrm{m} / \mathrm{s})$ & $0.345 \quad 0.277$ & $\begin{array}{ll}0.559 & 0.448\end{array}$ \\
\hline Critical displacement of kill fluid (L/s) & $2.892 \quad 2.872$ & $2.590 \quad 2.572$ \\
\hline Critical gas displacement $(\mathrm{L} / \mathrm{s})$ & $6.265 \quad 5.021$ & 5.6114 .497 \\
\hline Injection time of $3 \mathrm{~m}^{3}$ kill fluid (min) & $28.81 \quad 29.02$ & $19.30 \quad 19.44$ \\
\hline $\begin{array}{l}\text { Casing pressure after injection of } 3 \mathrm{~m}^{3} \\
\text { kill fluid (MPa) }\end{array}$ & 0.40 & 1.90 \\
\hline
\end{tabular}

Table 4 Values of relevant parameters for flooding

\begin{tabular}{lll}
\hline Basic parameters & In wellbore & In annulus \\
\hline Shut in casing pressure $(\mathrm{MPa})$ & 4.83 & 4.83 \\
Well depth $(\mathrm{m})$ & 347 & 347 \\
Wellhead temperature $\left({ }^{\circ} \mathrm{C}\right)$ & 23.85 & 23.85 \\
Temperature gradient $\left({ }^{\circ} \mathrm{C} / \mathrm{m}\right)$ & 0.015 & 0.015 \\
Inner diameter of casing $(\mathrm{m})$ & 0.152 & 0.152 \\
Outside diameter of drill pipe $(\mathrm{m})$ & 1 & 0.1016 \\
Kill fluid density $\left(\mathrm{kg} / \mathrm{m}^{3}\right)$ & 1000 & 1000 \\
Pump volume of killing fluid $\left(\mathrm{m}^{3}\right)$ & 5 & 5 \\
Gas density $\left(\mathrm{kg} / \mathrm{m}^{3}\right)$ & 31 & 31 \\
Well angle $\left({ }^{\circ}\right)$ & 0 & 0 \\
Surface tension of kill fluid $(\mathrm{N} / \mathrm{m})$ & 0.03 & 0.03 \\
Dynamic viscosity of killing fluid $\left(\mathrm{N} \mathrm{s} / \mathrm{m}^{2}\right)$ & 0.025 & 0.025
\end{tabular}


Table 5 Basic parameters of kill fluid

\begin{tabular}{lllll}
\hline $\begin{array}{l}\text { Experimental condition } \\
150{ }^{\circ} \mathrm{C} \times 16 \mathrm{~h}\end{array}$ & $\begin{array}{l}\mathrm{AV} \\
(\mathrm{mPa} \mathrm{s})\end{array}$ & $\begin{array}{l}\mathrm{PV} \\
(\mathrm{mPa} \mathrm{s})\end{array}$ & $\begin{array}{l}\mathrm{YP} \\
(\mathrm{Pa})\end{array}$ & $\begin{array}{l}\mathrm{FL} \\
(\mathrm{ml})\end{array}$ \\
\hline Before aging & 12 & 7 & 5 & 17 \\
After aging & 6 & 3 & 3 & 27 \\
\hline
\end{tabular}



Fig. 6 Critical displacement of flooding under different liquid viscosity

the formula are non-hazardous industrial molding products. The basic parameters of kill fluid are shown in Table 5 .

\section{The influence of the dynamic viscosity of the kill fluid}

In the process of empty well killing, the dynamic viscosity of killing fluid changes with the change of composition of killing fluid and temperature in the wellbore. In this paper, the minimum dynamic viscosity is $0.025 \mathrm{~N} \mathrm{~s} / \mathrm{m}^{2}$, and the maximum dynamic viscosity is $0.045 \mathrm{~N} \mathrm{~s} / \mathrm{m}^{2}$ for analysis and research.

As shown in Fig. 6: (1) As the dynamic viscosity of the kill fluid increases, the flooding curve moves downward, and the critical displacement of gas and liquid decreases; (2) Within the selectable displacement range of the kill fluid, the higher the dynamic viscosity of the kill fluid, the lower the critical velocity of flooding, and the easier it will be; (3) The influence of liquid viscosity in the wellbore on the critical displacement is consistent with that of the annulus.

As shown in Fig. 7a: As the dynamic viscosity of kill fluid increases, the critical displacement of kill fluid decreases.

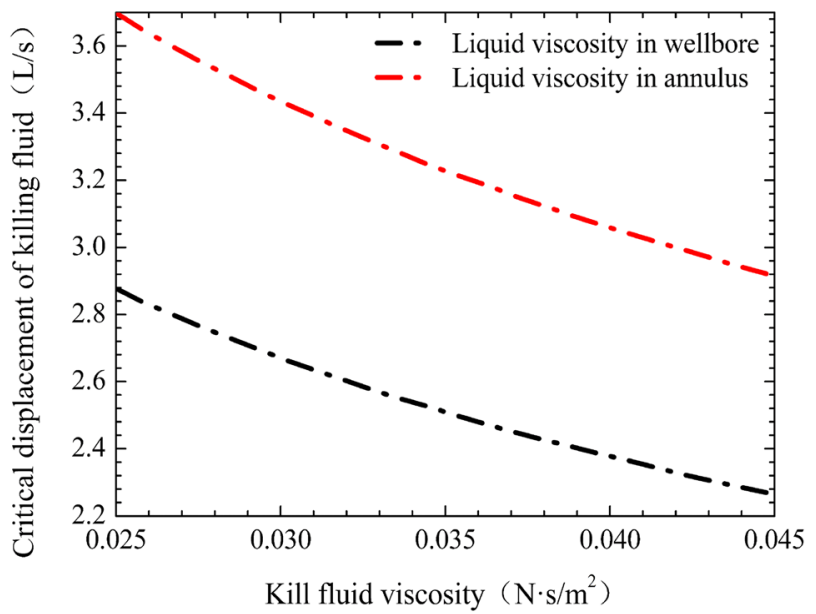

(a) The influence of liquid viscosity on kill fluid displacement

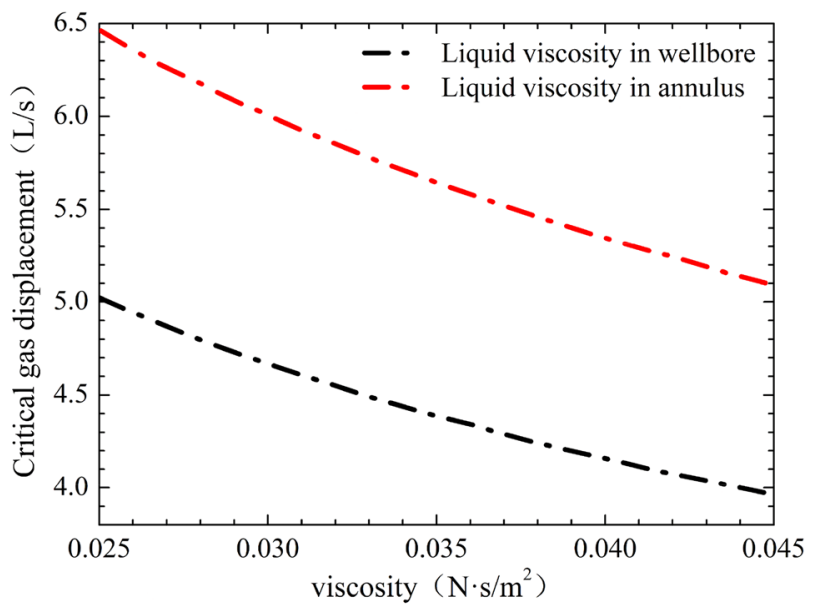

(b) The influence of liquid viscosity on gas displacement

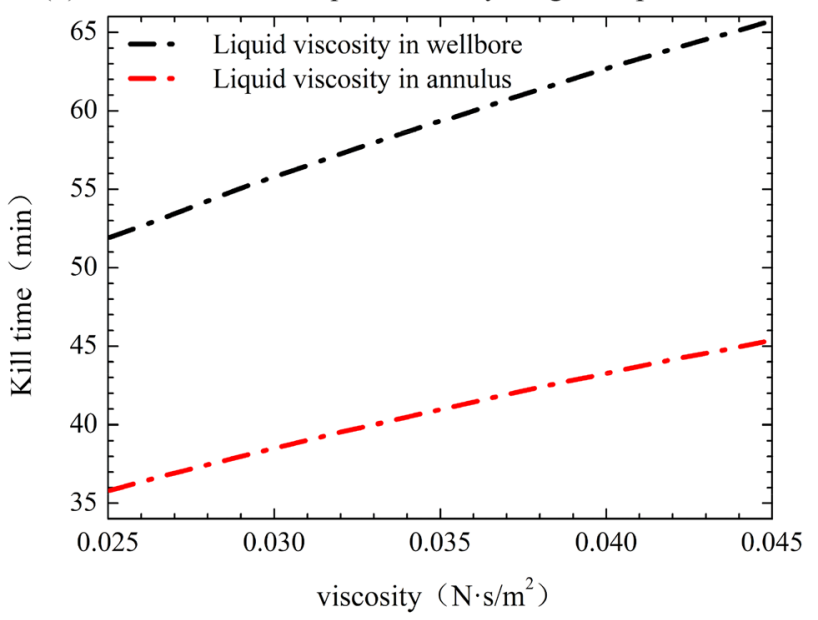

(c) The influence of liquid viscosity on kill time

Fig. 7 The influence of liquid viscosity on kill fluid displacement, gas displacement, and kill time 
Table 6 Calculation results under different kill fluid viscosity

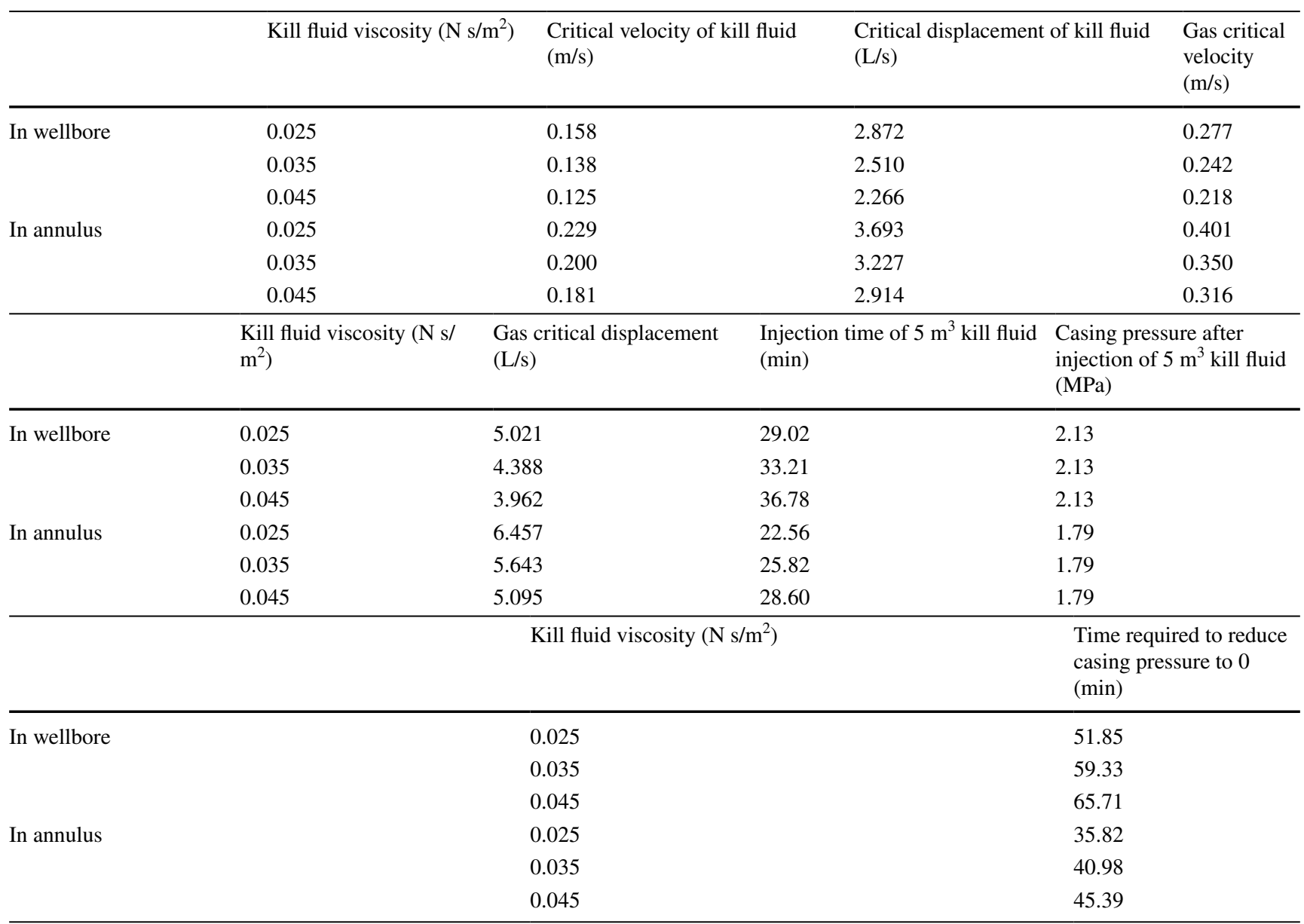

This is because the shear action of gas flow on kill fluid increases with the increase of viscosity, which reduces the critical displacement of kill fluid.

As shown in Fig. 7b: As the dynamic viscosity of kill fluid increases, the critical displacement of gas decreases. This is because the shear action of gas flow on kill fluid increases with the increase of viscosity, and a small gas flow rate can also provide sufficient shear force to cause flooding.

As shown in Fig. 7c: The killing time increases with the increase of viscosity. This is because that the increase of viscosity will lead to the decrease of gas-liquid critical displacement. However, the amount of kill fluid required to establish the balance between bottom hole pressure and formation pressure remains unchanged, so the kill time increases.

The calculation results under different kill fluid viscosities are shown in Table 6.

\section{The influence of liquid surface tension}

The surface tension of killing fluid varies with the killing fluid. In this paper, the minimum surface tension of killing fluid is $0.03 \mathrm{~N} / \mathrm{m}$, and the maximum surface tension of killing fluid is $0.05 \mathrm{~N} / \mathrm{m}$.

As shown in Fig. 8: With the increase of the surface tension of the killing fluid, the gas-liquid critical displacement 


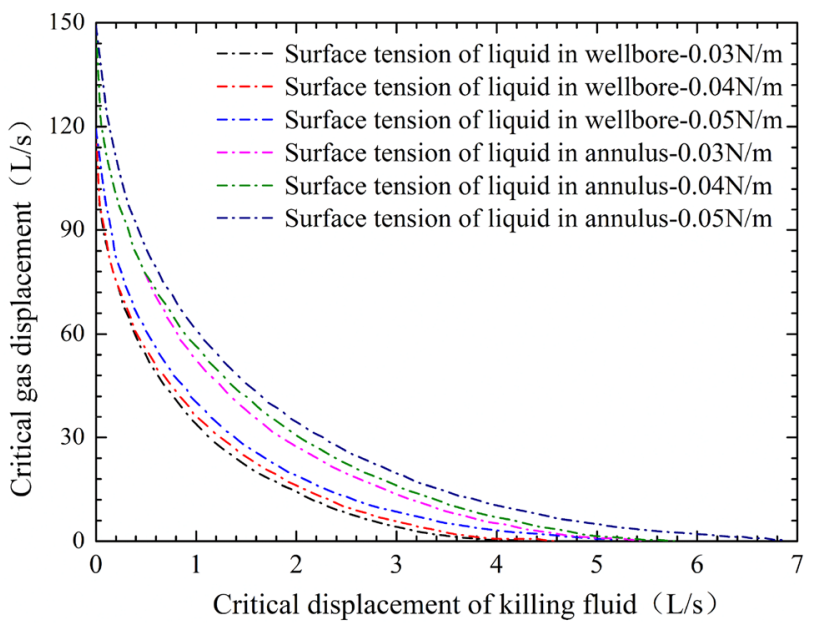

Fig. 8 Critical displacement of flooding under different surface tensions

curve increases, indicating that the greater the surface tension of the liquid, the higher the critical gas-liquid velocity when flooding occurs, and the greater the surface tension of the killing fluid; In the case of gas-liquid countercurrent contact, the stronger the ability to resist the sheer force of gas flow, the less prone to flooding.

As shown in Fig. 9a: When the surface tension of kill fluid is greater, the critical displacement of kill fluid increases, but the variation range is not large. Under the change of liquid viscosity of the same order of magnitude, the critical displacement of kill fluid decreases by $0.606 \mathrm{~L} / \mathrm{s}$, while when the surface tension of kill fluid changes, the critical displacement of kill fluid increases by $0.304 \mathrm{~L} / \mathrm{s}$. This shows that the influence of physical parameters medium pressure well fluid viscosity on the critical displacement of kill fluid is greater than that of surface tension.

As shown in Fig. 9b: The critical gas displacement increases with the increase of the surface tension of the well-killing fluid. With the change of liquid viscosity of the same order of magnitude, the critical gas displacement decreases by $1.059 \mathrm{~L} / \mathrm{s}$, and with the change of kill fluid surface tension of the same order of magnitude, the critical gas displacement increases by $0.533 \mathrm{~L} / \mathrm{s}$. It also shows that the influence of physical parameters medium pressure well fluid viscosity on critical gas displacement is greater than that of surface tension.

As shown in Fig. 9c: The kill time decreases with the increase of kill fluid surface tension because the kill fluid

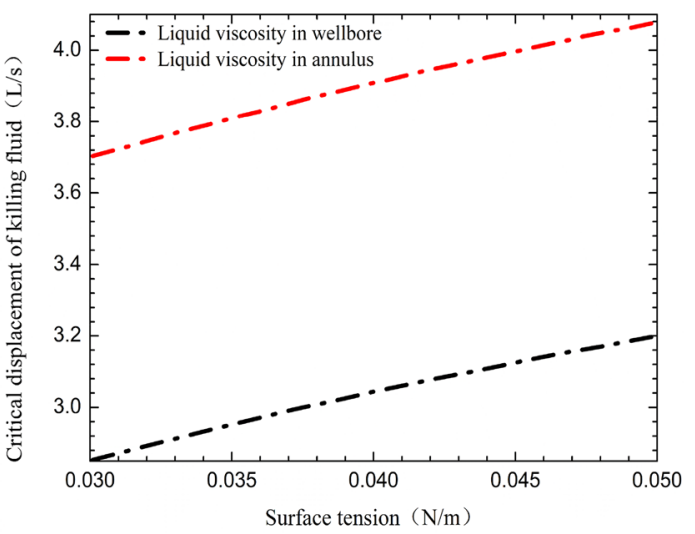

(a) The influence of surface tension of kill fluid on kill fluid displacement

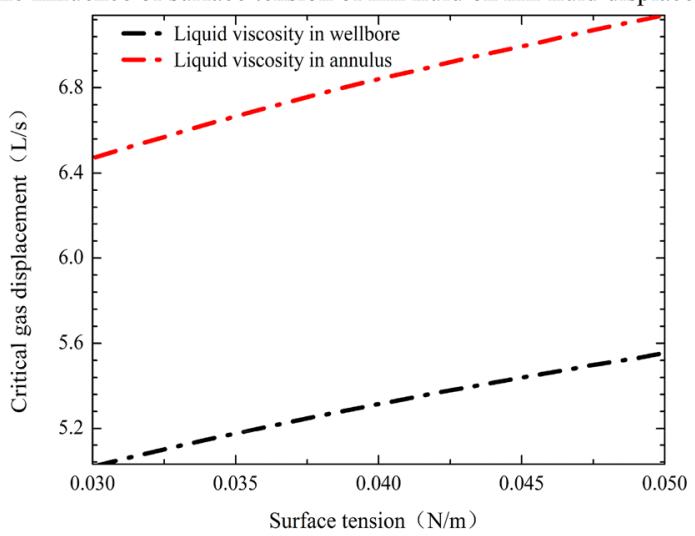

(b) The influence of surface tension of kill fluid on gas displacement

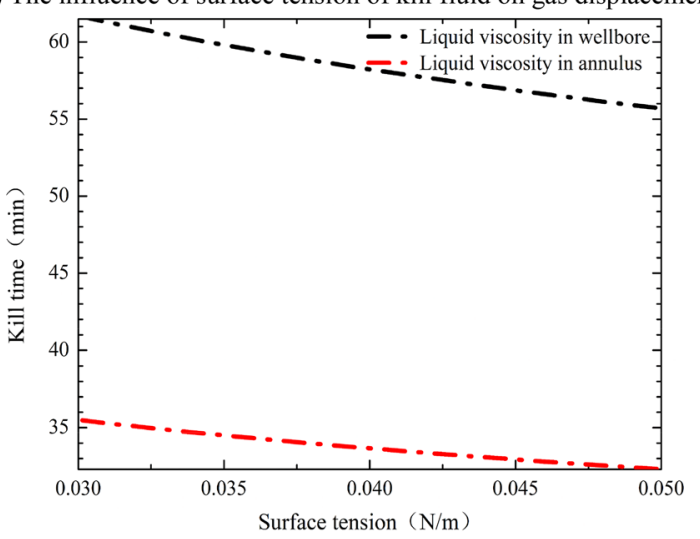

(c) The influence of surface tension of kill fluid on kill time

Fig. 9 The influence of surface tension of kill fluid on kill fluid displacement, gas displacement, and kill time

displacement and gas displacement increase with the increase of kill fluid surface tension.

The calculation results under different kill fluid surface tension are shown in Table 7. 
Table 7 Calculation results under different kill fluid surface tension

\begin{tabular}{|c|c|c|c|c|c|c|}
\hline & $\begin{array}{l}\text { Surface tension of kill fluid } \\
(\mathrm{N} / \mathrm{m})\end{array}$ & \multicolumn{2}{|c|}{$\begin{array}{l}\text { Critical velocity of kill fluid } \\
(\mathrm{m} / \mathrm{s})\end{array}$} & \multicolumn{2}{|c|}{$\begin{array}{l}\text { Critical displacement of kill fluid } \\
(\mathrm{L} / \mathrm{s})\end{array}$} & $\begin{array}{l}\text { Gas critical } \\
\text { velocity } \\
(\mathrm{m} / \mathrm{s})\end{array}$ \\
\hline \multirow[t]{3}{*}{ In wellbore } & 0.03 & 0.158 & & 2.872 & & 0.277 \\
\hline & 0.04 & 0.168 & & 3.040 & & 0.293 \\
\hline & 0.05 & 0.171 & & 3.176 & & 0.306 \\
\hline \multirow[t]{4}{*}{ In annulus } & 0.03 & 0.229 & & 3.693 & & 0.401 \\
\hline & 0.04 & 0.243 & & 3.909 & & 0.424 \\
\hline & 0.05 & 0.253 & & 4.085 & & 0.443 \\
\hline & $\begin{array}{l}\text { Surface tension of kill fluid } \\
(\mathrm{N} / \mathrm{m})\end{array}$ & $\begin{array}{l}\text { Gas critical displacement } \\
(\mathrm{L} / \mathrm{s})\end{array}$ & $\begin{array}{l}\text { Injecti } \\
\text { fluid ( }\end{array}$ & time of $5 \mathrm{~m}^{3} \mathrm{kill}$ & $\begin{array}{l}\text { Casing press } \\
\text { injection of } \\
(\mathrm{MPa})\end{array}$ & $\begin{array}{l}\text { ure after } \\
\mathrm{m}^{3} \text { kill fluid }\end{array}$ \\
\hline \multirow[t]{3}{*}{ In wellbore } & 0.03 & 5.021 & 29.02 & & 2.13 & \\
\hline & 0.04 & 5.315 & 27.41 & & 2.13 & \\
\hline & 0.05 & 5.554 & 26.24 & & 2.13 & \\
\hline \multirow[t]{4}{*}{ In annulus } & 0.03 & 6.457 & 22.56 & & 1.79 & \\
\hline & 0.04 & 6.836 & 21.32 & & 1.79 & \\
\hline & 0.05 & 7.142 & 20.40 & & 1.79 & \\
\hline & \multicolumn{4}{|c|}{ Surface tension of kill fluid (N/m) } & \multicolumn{2}{|c|}{$\begin{array}{l}\text { Time required to reduce } \\
\text { casing pressure to } 0 \\
(\mathrm{~min})\end{array}$} \\
\hline \multirow[t]{3}{*}{ In wellbore } & \multicolumn{3}{|c|}{0.03} & \multicolumn{3}{|c|}{51.85} \\
\hline & \multicolumn{3}{|c|}{0.04} & \multicolumn{3}{|c|}{48.98} \\
\hline & \multicolumn{3}{|c|}{0.05} & \multicolumn{3}{|c|}{46.88} \\
\hline \multirow[t]{3}{*}{ In annulus } & \multicolumn{3}{|c|}{0.03} & \multicolumn{3}{|c|}{35.82} \\
\hline & \multicolumn{3}{|c|}{0.04} & \multicolumn{3}{|c|}{33.83} \\
\hline & \multicolumn{3}{|c|}{0.05} & \multicolumn{3}{|c|}{32.38} \\
\hline
\end{tabular}

\section{The influence of gas density}

The gas density in the well is related to pressure, temperature, and gas composition. When the pressure and temperature in the well are constant, the gas with high molecular weight has a higher density. In this paper, the minimum gas density of $30 \mathrm{~kg} / \mathrm{m}^{3}$ and the maximum gas density of $60 \mathrm{~kg} / \mathrm{m}^{3}$ are selected for calculation and analysis.

As shown in Fig. 10, the larger the gas density, the smaller the critical displacement of the flooding. With the increase of gas density, the sheer force of gas to liquid increases, which makes flooding more likely to occur. Therefore, the larger the gas density, the smaller the critical displacement required for liquid flooding.

As shown in Fig. 11a, b, both kill fluid and critical gas displacement decrease when the gas density increases.

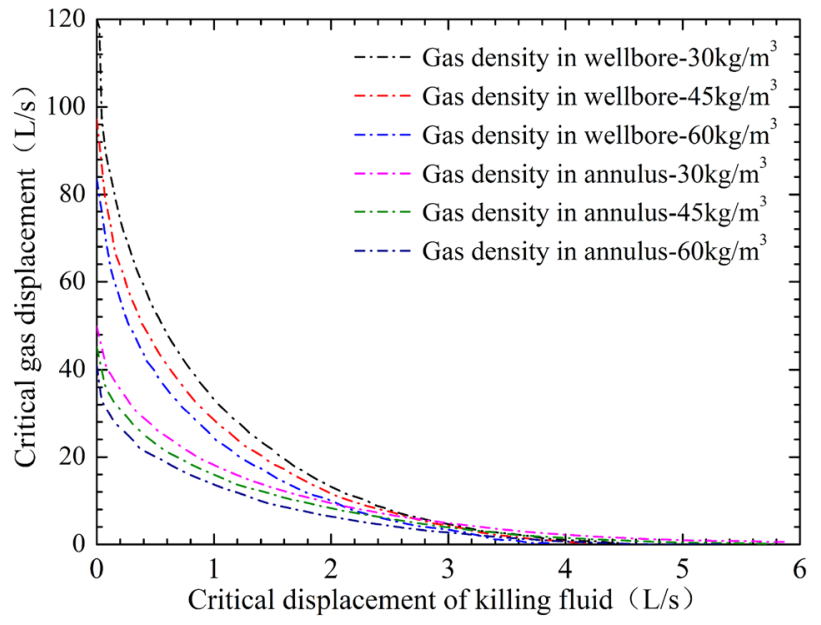

Fig. 10 Critical displacement of liquid flooding at different gas densities 
Therefore, in the process of dynamic displacement killing, if the gas composition discharged from the choke line changes and the relative molecular weight of the gas increases, the displacement of the killing fluid and gas should be reduced in time to prevent flooding.

As shown in Fig. 11c: As the gas density increases, the gas-liquid critical displacement decreases, and the killing time decreases with the rise in gas density.

The calculation results under different gas densities are shown in Table 8.

\section{The influence of killing fluid density}

The killing fluid density directly affects the hydrostatic pressure provided by the unit length of the liquid column in the wellbore. In the killing process, the density of the killing fluid needs to be considered and selected based on the combination of the formation pressure and the maximum loss pressure of the formation. In this paper, the minimum killing fluid density of $1000 \mathrm{~kg} / \mathrm{m}^{3}$ and the maximum killing fluid density of $2000 \mathrm{~kg} / \mathrm{m}^{3}$ are selected for calculation and analysis.

As shown in Fig. 12, with the increase of kill fluid density, the curve of gas-liquid critical displacement moves up, and the gas-liquid critical displacement increases.

As shown in Fig. 13a: The greater the density of the kill fluid, the greater the critical displacement of the kill fluid. The main reason is that with the increase of killing fluid density, the droplets with the same diameter are more difficult to be carried by gas, due to the greater gravity. Secondly, under the action of equal gas shear force, the droplets with the same diameter and greater density have greater inertia force and mass force, and the ability to resist gas shear is also enhanced.

As shown in Fig. 13b: With the increase of kill fluid density, the critical gas displacement also increases, mainly because the gravity and inertia force of the same volume of droplets increase, the shear effect of gas flow on liquid flow becomes more complex, and the liquid carrying degree becomes weaker. This means that when the kill fluid density increases, the gas displacement can be appropriately increased to reduce the kill time.

As shown in Fig. 13c, the critical displacement of gas and liquid increases with the increase of kill fluid density. At this time, the time required for well-killing decreases with the increase of kill fluid density.

The calculation results under different kill fluid densities are shown in Table 9.

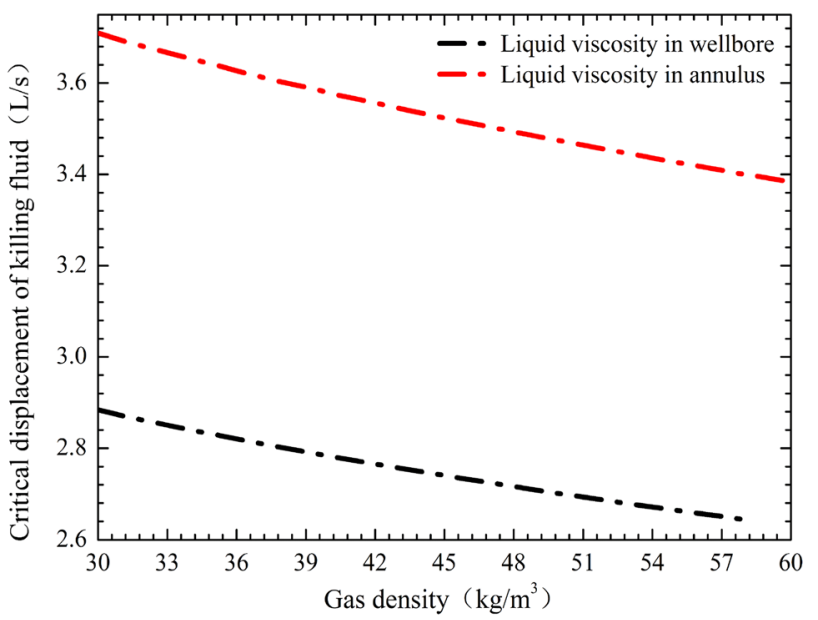

(a) The influence of gas density on kill fluid displacement

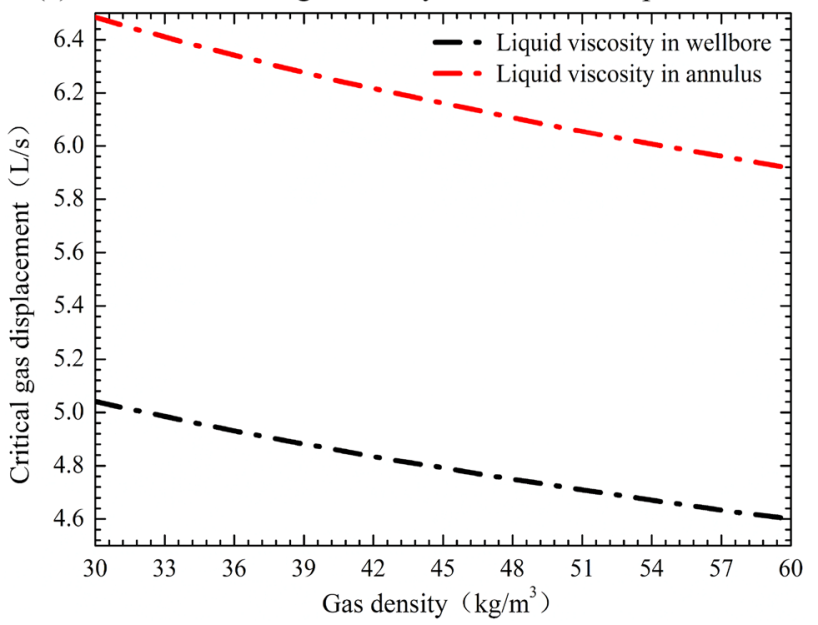

(b) The influence of gas density on gas displacement

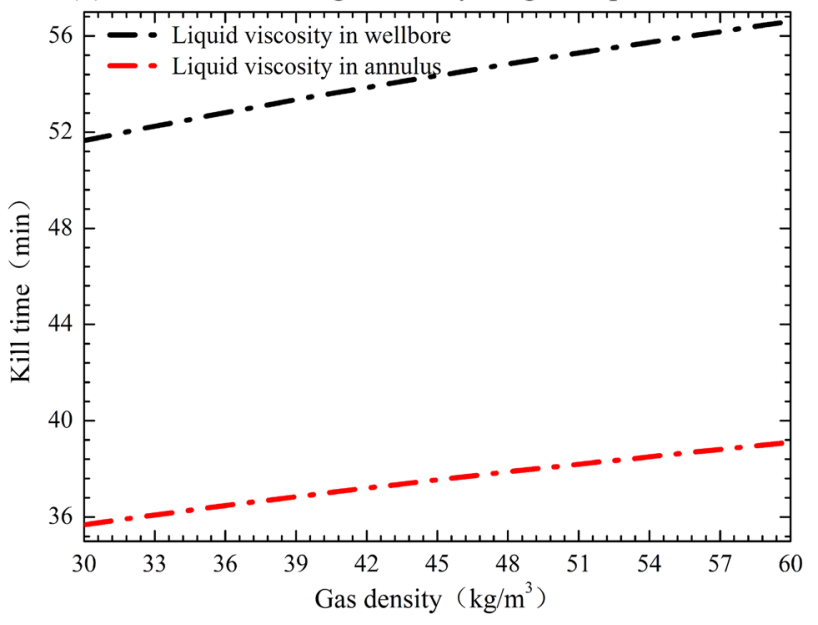

(c) The influence of gas density on kill time

Fig. 11 The influence of gas density on kill fluid displacement, gas displacement, and kill time 
Table 8 Calculation results under different gas densities

\begin{tabular}{|c|c|c|c|c|c|c|}
\hline \multirow{2}{*}{ In wellbore } & Gas density $\left(\mathrm{kg} / \mathrm{m}^{3}\right)$ & \multicolumn{2}{|c|}{$\begin{array}{l}\text { Critical velocity of kill fluid } \\
(\mathrm{m} / \mathrm{s})\end{array}$} & \multicolumn{2}{|c|}{$\begin{array}{l}\text { Critical displacement of kill fluid } \\
(\mathrm{L} / \mathrm{s})\end{array}$} & \multirow{2}{*}{$\begin{array}{l}\begin{array}{l}\text { Gas critical } \\
\text { velocity } \\
(\mathrm{m} / \mathrm{s})\end{array} \\
0.278\end{array}$} \\
\hline & 30 & 0.159 & & 2.883 & & \\
\hline & 45 & 0.151 & & 2.740 & & 0.264 \\
\hline & 60 & 0.145 & & 2.631 & & 0.254 \\
\hline \multirow[t]{4}{*}{ In annulus } & 30 & 0.230 & & 3.707 & & 0.402 \\
\hline & 45 & 0.219 & & 3.524 & & 0.382 \\
\hline & 60 & 0.210 & & 3.383 & & 0.367 \\
\hline & Gas density $\left(\mathrm{kg} / \mathrm{m}^{3}\right)$ & $\begin{array}{l}\text { Gas critical displacement } \\
(\mathrm{L} / \mathrm{s})\end{array}$ & $\begin{array}{l}\text { Injec } \\
(\mathrm{min})\end{array}$ & time of $5 \mathrm{~m}^{3}$ kill fluid & $\begin{array}{l}\text { Casing pre } \\
\text { injection o } \\
(\mathrm{MPa})\end{array}$ & $\begin{array}{l}\text { ure after } \\
\mathrm{m}^{3} \text { kill fluid }\end{array}$ \\
\hline \multirow[t]{3}{*}{ In wellbore } & 30 & 5.041 & 28.91 & & 2.13 & \\
\hline & 45 & 4.791 & 30.41 & & 2.13 & \\
\hline & 60 & 4.600 & 31.68 & & 2.13 & \\
\hline \multirow[t]{4}{*}{ In annulus } & 30 & 6.482 & 22.48 & & 1.79 & \\
\hline & 45 & 6.161 & 23.65 & & 1.79 & \\
\hline & 60 & 5.915 & 24.63 & & 1.79 & \\
\hline & \multicolumn{4}{|c|}{ Gas density $\left(\mathrm{kg} / \mathrm{m}^{3}\right)$} & \multicolumn{2}{|c|}{$\begin{array}{l}\text { Time required to reduce } \\
\text { casing pressure to } 0 \\
(\mathrm{~min})\end{array}$} \\
\hline \multirow[t]{3}{*}{ In wellbore } & \multicolumn{3}{|c|}{30} & \multicolumn{3}{|c|}{51.65} \\
\hline & \multicolumn{3}{|c|}{45} & \multicolumn{3}{|c|}{54.35} \\
\hline & \multicolumn{3}{|c|}{60} & \multicolumn{3}{|c|}{56.60} \\
\hline \multirow[t]{3}{*}{ In annulus } & \multicolumn{3}{|c|}{30} & \multicolumn{3}{|c|}{35.68} \\
\hline & \multicolumn{3}{|c|}{45} & \multicolumn{3}{|c|}{37.54} \\
\hline & \multicolumn{3}{|c|}{60} & \multicolumn{3}{|c|}{39.10} \\
\hline
\end{tabular}

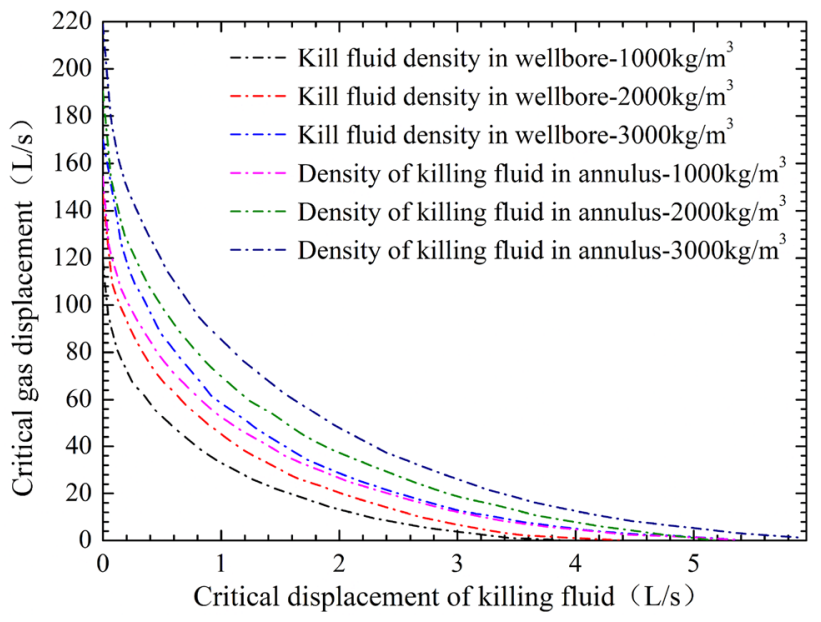

Fig. 12 Critical flooding displacement under different kill fluid densities

\section{Analysis of the influence of engineering parameters related to flooding}

\section{The influence of casing inner diameter}

Because of the change of casing inner diameter, the casing cross-sectional area also changes, and the trend of flooding critical displacement and flooding critical velocity is different, so they need to be analyzed separately. In this paper, the minimum inner diameter of the casing is $0.152 \mathrm{~m}$ (6 in), and the maximum inner diameter of the casing is $0.2286 \mathrm{~m}$ (9 in) for calculation and analysis.

As shown in Fig. 14: As the inner diameter of the casing increases, the critical velocity curve of liquid flooding moves upward, indicating that the larger the inner diameter of the 


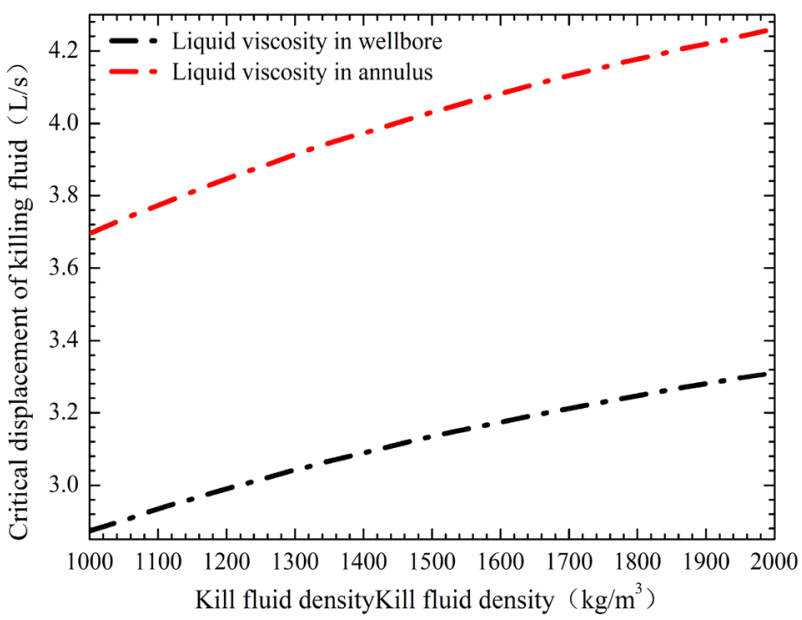

(a) The influence of kill fluid density on kill fluid displacement

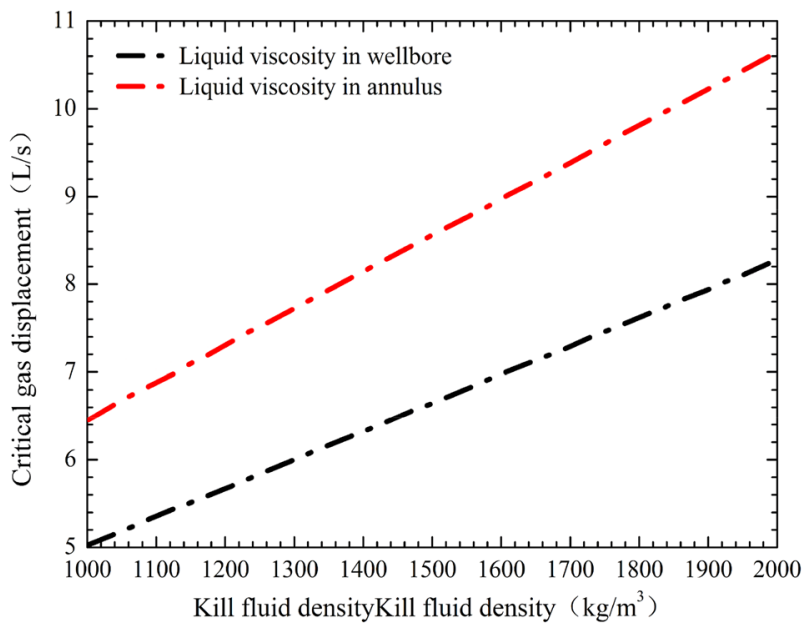

(b) The influence of kill fluid density on gas displacement

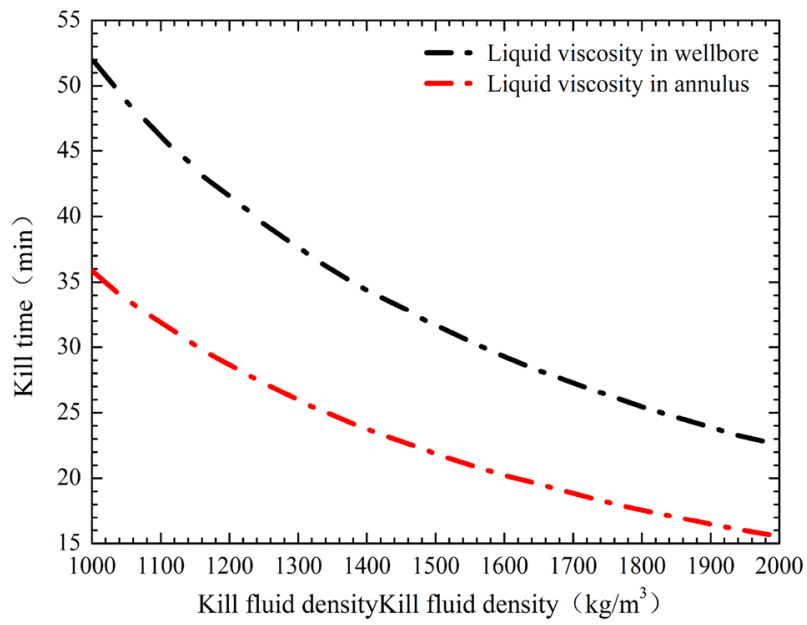

(c) The influence of kill fluid density on kill time

Fig. 13 The influence of kill fluid density on kill fluid displacement, gas displacement, and kill time

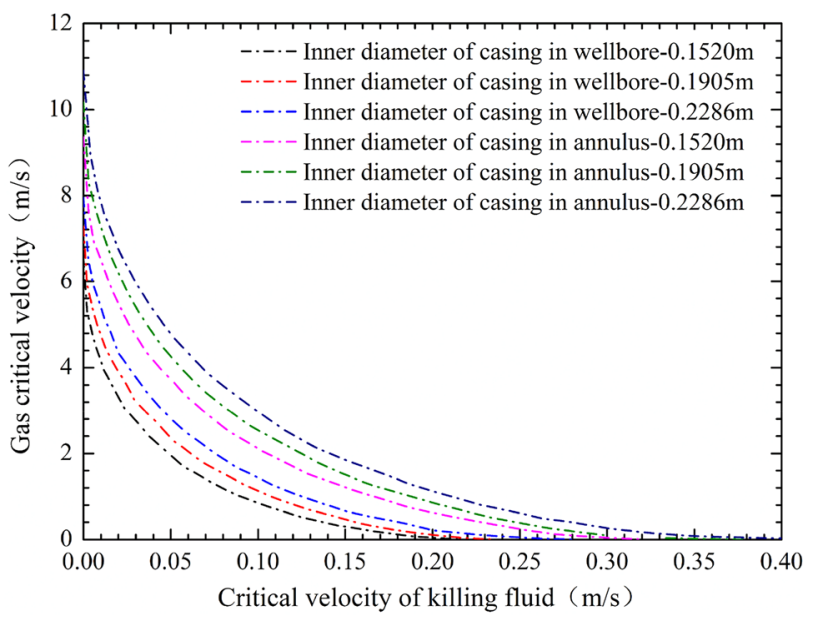

Fig. 14 Critical displacement of flooding under different casing diameters

casing, the critical liquid flooding velocity of gas and liquid increases.

As shown in Fig. 15: The flooding critical displacement curve moves upward with the increase of casing inner diameter, and the value range of kill fluid critical displacement and gas displacement change greatly. This is because the increase of the inner diameter of the casing increases the cross-sectional area of the flow area, which amplifies the increasing trend of the flooding velocity.

As shown in Fig. 16a: With the increase of casing inner diameter, the critical displacement of kill fluid increases. This is because after the increase of casing inner diameter, the actual velocity of gas flow in the wellbore decreases, which weakens its sheer effect on the liquid, and the critical displacement of liquid increases.

As shown in Fig. 16b: As the inner diameter of the casing increases, the critical gas displacement increases. This is because a more significant gas displacement is required to provide the interfacial shear force required for flooding.

As shown in Fig. 16c: As the inner diameter of the casing increases, the critical displacement of the kill fluid becomes more significant, and the time required to kill the well will decrease.

The calculation results under different casing diameters are shown in Table 10. 
Table 9 Calculation results under different kill fluid densities

\begin{tabular}{|c|c|c|c|c|c|c|}
\hline & Kill fluid density $\left(\mathrm{kg} / \mathrm{m}^{3}\right)$ & \multicolumn{2}{|c|}{$\begin{array}{l}\text { Critical velocity of kill fluid } \\
(\mathrm{m} / \mathrm{s})\end{array}$} & \multicolumn{2}{|c|}{$\begin{array}{l}\text { Critical displacement of kill fluid } \\
(\mathrm{L} / \mathrm{s})\end{array}$} & $\begin{array}{l}\text { Gas critical } \\
\text { velocity } \\
(\mathrm{m} / \mathrm{s})\end{array}$ \\
\hline \multirow[t]{3}{*}{ In wellbore } & 1000 & 0.158 & & 2.872 & & 0.277 \\
\hline & 1500 & 0.173 & & 3.134 & & 0.367 \\
\hline & 2000 & 0.182 & & 3.311 & & 0.456 \\
\hline \multirow[t]{4}{*}{ In annulus } & 1000 & 0.229 & & 3.693 & & 0.401 \\
\hline & 1500 & 0.250 & & 4.030 & & 0.531 \\
\hline & 2000 & 0.264 & & 4.258 & & 0.660 \\
\hline & Kill fluid density $\left(\mathrm{kg} / \mathrm{m}^{3}\right)$ & $\begin{array}{l}\text { Gas critical displacement } \\
(\mathrm{L} / \mathrm{s})\end{array}$ & $\begin{array}{l}\text { Injec } \\
(\mathrm{min}\end{array}$ & time of $5 \mathrm{~m}^{3}$ kill fluid & $\begin{array}{l}\text { Casing pres } \\
\text { injection of } \\
(\mathrm{MPa})\end{array}$ & $\begin{array}{l}\text { ure after } \\
\mathrm{m}^{3} \text { kill fluid }\end{array}$ \\
\hline \multirow[t]{3}{*}{ In wellbore } & 1000 & 5.021 & 17.4 & & 3.21 & \\
\hline & 1500 & 6.652 & 15.9 & & 2.40 & \\
\hline & 2000 & 8.267 & 15.1 & & 1.59 & \\
\hline \multirow[t]{4}{*}{ In annulus } & 1000 & 6.457 & 13.5 & & 3.01 & \\
\hline & 1500 & 8.554 & 12.4 & & 2.09 & \\
\hline & 2000 & 10.631 & 11.7 & & 1.18 & \\
\hline & \multicolumn{4}{|c|}{ Kill fluid density $\left(\mathrm{kg} / \mathrm{m}^{3}\right)$} & \multicolumn{2}{|c|}{$\begin{array}{l}\text { Time required to reduce } \\
\text { casing pressure to } 0 \\
(\mathrm{~min})\end{array}$} \\
\hline \multirow[t]{3}{*}{ In wellbore } & \multicolumn{3}{|c|}{1000} & \multicolumn{3}{|c|}{51.85} \\
\hline & \multicolumn{3}{|c|}{1500} & \multicolumn{3}{|c|}{31.68} \\
\hline & \multicolumn{3}{|c|}{2000} & \multicolumn{3}{|c|}{22.49} \\
\hline \multirow[t]{3}{*}{ In annulus } & \multicolumn{3}{|c|}{1000} & \multicolumn{3}{|c|}{35.82} \\
\hline & \multicolumn{3}{|c|}{1500} & \multicolumn{3}{|c|}{21.88} \\
\hline & \multicolumn{3}{|c|}{2000} & \multicolumn{3}{|c|}{15.53} \\
\hline
\end{tabular}

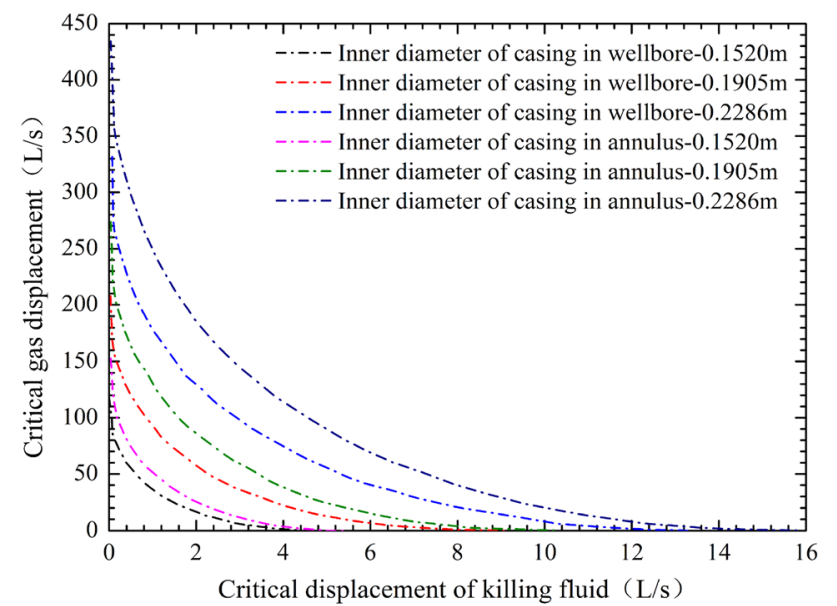

Fig. 15 Critical displacement of flooding under different casing inner diameter

\section{The influence of casing pressure}

In this paper, the minimum casing pressure is $3.10 \mathrm{MPa}$ (the gas density in the well is $19.9 \mathrm{~kg} / \mathrm{m}^{3}$ ), and the maximum casing pressure is $4.83 \mathrm{MPa}\left(31.0 \mathrm{~kg} / \mathrm{m}^{3}\right)$ for calculation and analysis.

As shown in Fig. 17: As the casing pressure increases, the critical displacement of flooding decreases. This is because casing pressure has no direct effect on the essential removal of flooding. Still, it is mainly because the gas density in the well increases after the casing pressure increases, which 


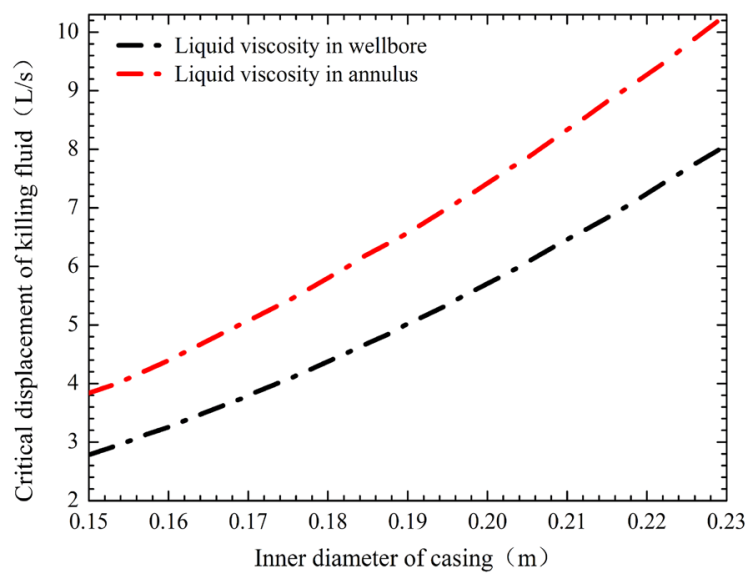

(a) The influence of casing inner diameter on kill fluid displacement

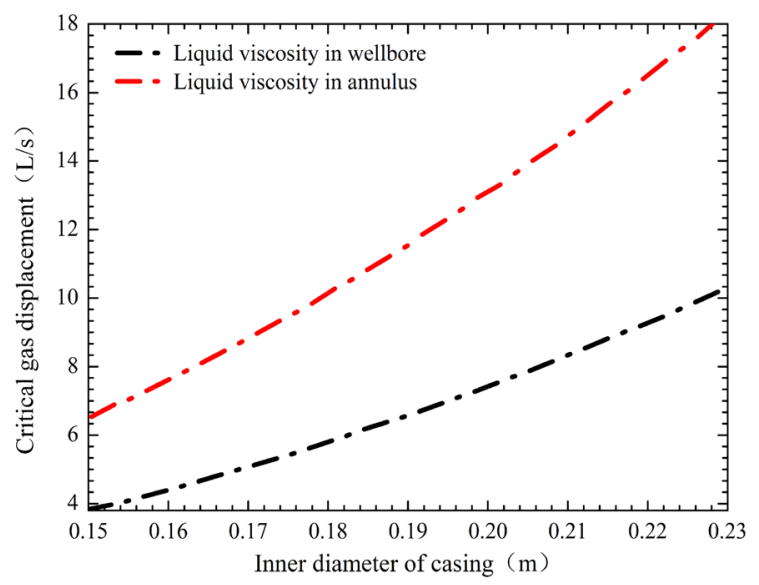

(b) The influence of casing inner diameter on gas displacement

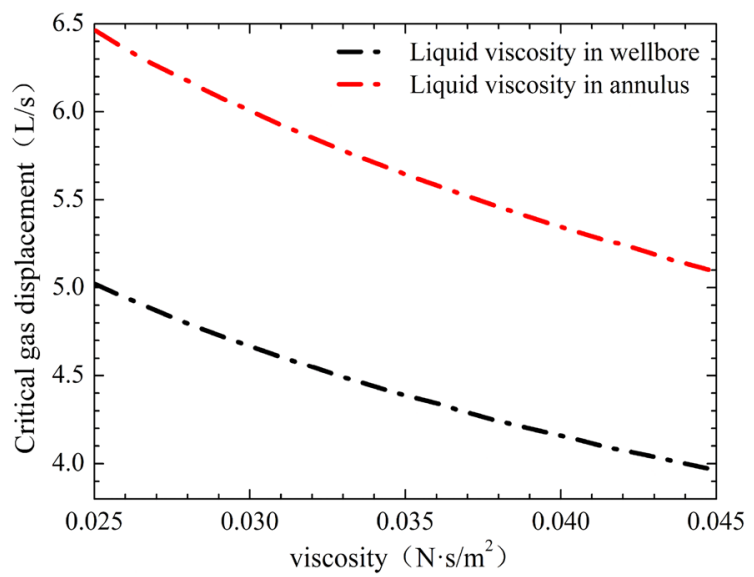

(c) The influence of casing inner diameter on kill time

Fig. 16 The influence of casing inner diameter on kill fluid displacement, gas displacement, and kill time reduces the critical displacement of flooding. The casing pressure change acts on the gas density in the well, and the gas density change in the well acts on the critical displacement of the flooding.

As shown in Fig. 18a, b: The casing pressure increases and the critical displacement of the kill fluid decreases, but the range of change is not extensive. At the same time, the casing pressure increases and the critical gas displacement decreases, and the range of change is slightly larger than that of the kill fluid displacement. It shows that the critical displacement of gas is more sensitive to the shift in casing pressure than the critical displacement of kill fluid to the change of casing pressure.

As shown in Fig. 18c: As the casing pressure increases, the critical displacement of the kill fluid decreases, and the height of the static liquid column required to balance the formation pressure increases, which greatly increases the kill time.

The calculation results under different casing pressures are shown in Table 11.

\section{The influence of well angle}

This paper selects the minimum deviation angle of $0^{\circ}$ and the maximum deviation angle of $60^{\circ}$ for research and analysis.

As shown in Fig. 19, the flooding critical displacement curve moves down with the increase of well deviation angle. It shows that the smaller the well deviation angle, the more likely flooding occurs. This is because the increase of well deviation angle, the increase of liquid film thickness, and the increase of liquid film fluctuation lead to the decrease of flooding velocity and the decrease of critical displacement.

As shown in Fig. 20a, b: The critical displacement of gas and liquid decreases with the increase of well deviation angle. When the well deviation angle is small, the critical displacement of gas and liquid decreases slowly with the increase of well deviation angle. When the well deviation angle is large, the critical displacement of gas and liquid decreases quickly with the increase of well deviation angle. Therefore, the critical displacement of gas and liquid is more sensitive to the change of well deviation angle, when the well deviation angle changes between small areas. 
Table 10 Calculation results under different casing diameters

\begin{tabular}{|c|c|c|c|c|c|c|}
\hline & Casing inner diameter $(\mathrm{m})$ & \multicolumn{2}{|c|}{$\begin{array}{l}\text { Critical velocity of kill fluid } \\
(\mathrm{m} / \mathrm{s})\end{array}$} & \multicolumn{2}{|c|}{$\begin{array}{l}\text { Critical displacement of kill fluid } \\
(\mathrm{L} / \mathrm{s})\end{array}$} & \multirow{2}{*}{$\begin{array}{l}\begin{array}{l}\text { Gas critical } \\
\text { velocity } \\
(\mathrm{m} / \mathrm{s})\end{array} \\
0.277\end{array}$} \\
\hline \multirow[t]{3}{*}{ In wellbore } & 0.152 & 0.158 & & 2.872 & & \\
\hline & 0.1905 & 0.177 & & 5.050 & & 0.310 \\
\hline & 0.2286 & 0.194 & & 7.966 & & 0.339 \\
\hline \multirow[t]{4}{*}{ In annulus } & 0.152 & 0.229 & & 3.693 & & 0.401 \\
\hline & 0.1905 & 0.250 & & 6.617 & & 0.437 \\
\hline & 0.2286 & 0.269 & & 10.493 & & 0.470 \\
\hline & $\begin{array}{l}\text { Casing inner diameter } \\
\text { (m) }\end{array}$ & $\begin{array}{l}\text { Gas critical displacement } \\
(\mathrm{L} / \mathrm{s})\end{array}$ & $\begin{array}{l}\text { Inject } \\
(\min )\end{array}$ & time of $5 \mathrm{~m}^{3}$ kill fluid & $\begin{array}{l}\text { Casing pres } \\
\text { injection of } \\
(\mathrm{MPa})\end{array}$ & $\begin{array}{l}\text { Ire after } \\
\mathrm{m}^{3} \text { kill fluid }\end{array}$ \\
\hline \multirow[t]{3}{*}{ In wellbore } & 0.152 & 5.021 & 29.02 & & 2.13 & \\
\hline & 0.1905 & 8.830 & 16.50 & & 3.11 & \\
\hline & 0.2286 & 13.93 & 10.46 & & 3.64 & \\
\hline \multirow[t]{4}{*}{ In annulus } & 0.152 & 6.457 & 22.56 & & 1.79 & \\
\hline & 0.1905 & 11.569 & 12.59 & & 2.98 & \\
\hline & 0.2286 & 18.346 & 7.94 & & 3.57 & \\
\hline & \multicolumn{4}{|c|}{ Casing inner diameter $(\mathrm{m})$} & \multicolumn{2}{|c|}{$\begin{array}{l}\text { Time required to reduce } \\
\text { casing pressure to } 0 \\
\text { (min) }\end{array}$} \\
\hline \multirow[t]{3}{*}{ In wellbore } & \multicolumn{3}{|c|}{0.152} & \multicolumn{3}{|c|}{51.85} \\
\hline & \multicolumn{3}{|c|}{0.1905} & \multicolumn{3}{|c|}{46.31} \\
\hline & \multicolumn{3}{|c|}{0.2286} & \multicolumn{3}{|c|}{42.28} \\
\hline \multirow[t]{3}{*}{ In annulus } & \multicolumn{3}{|c|}{0.152} & \multicolumn{3}{|c|}{35.81} \\
\hline & \multicolumn{3}{|c|}{0.1905} & \multicolumn{3}{|c|}{32.83} \\
\hline & \multicolumn{3}{|c|}{0.2286} & \multicolumn{3}{|c|}{30.51} \\
\hline
\end{tabular}

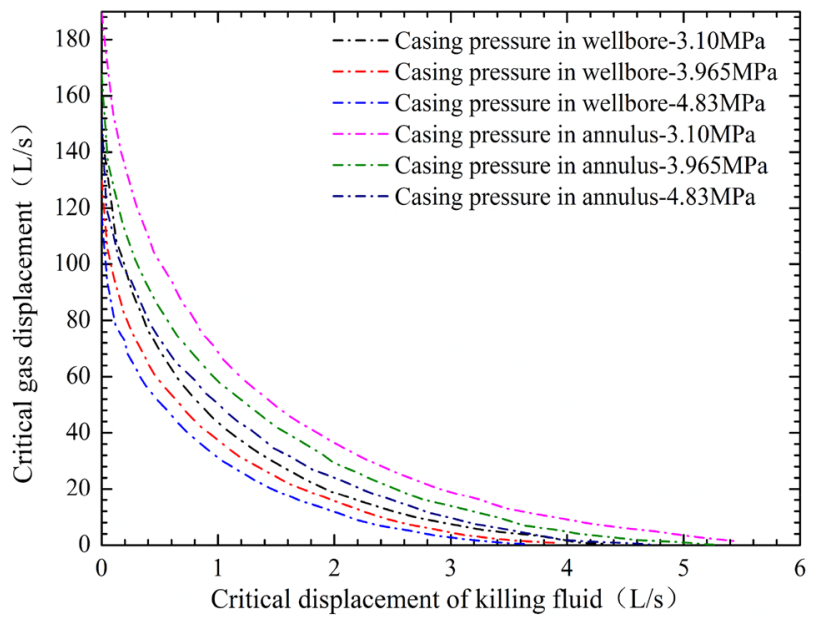

Fig. 17 The influence of casing pressure on the critical displacement of flooding
As shown in Fig. 20c: With the increase of well deviation angle, the killing time increases, which is caused by the decrease of critical gas-liquid displacement.

The calculation results under different well deviation angles are shown in Table 12.

\section{The influence of drill pipe outer diameter}

In this paper, the smallest drill pipe outer diameter is $0.0508 \mathrm{~m} \mathrm{(2} \mathrm{in),} \mathrm{and} \mathrm{the} \mathrm{largest} \mathrm{casing} \mathrm{inner} \mathrm{diameter} \mathrm{is}$ $0.1016 \mathrm{~m}$ (4 in) for calculation and analysis.

As shown in Fig. 21, the outside diameter of the drill pipe increases the critical velocity curve of gas-liquid, which is 


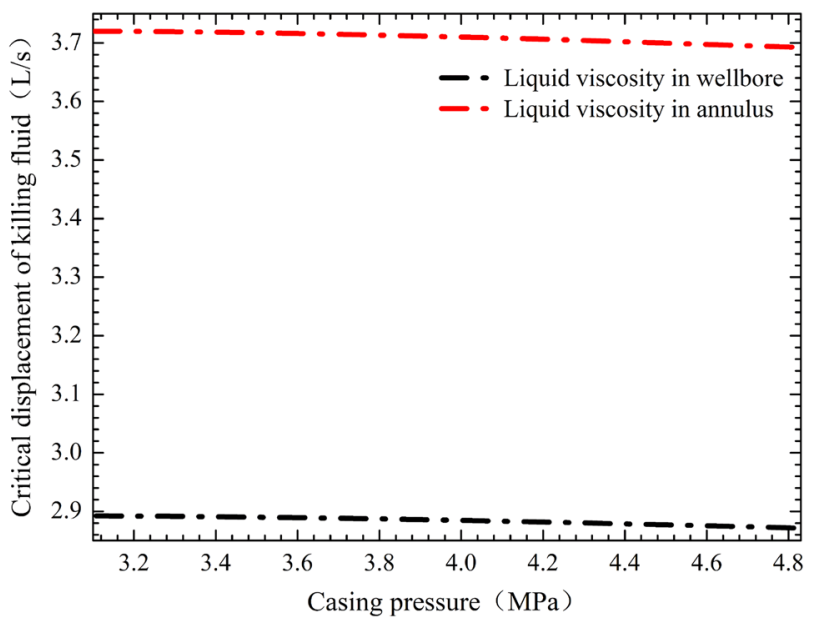

(a) The influence of casing pressure on kill fluid displacement

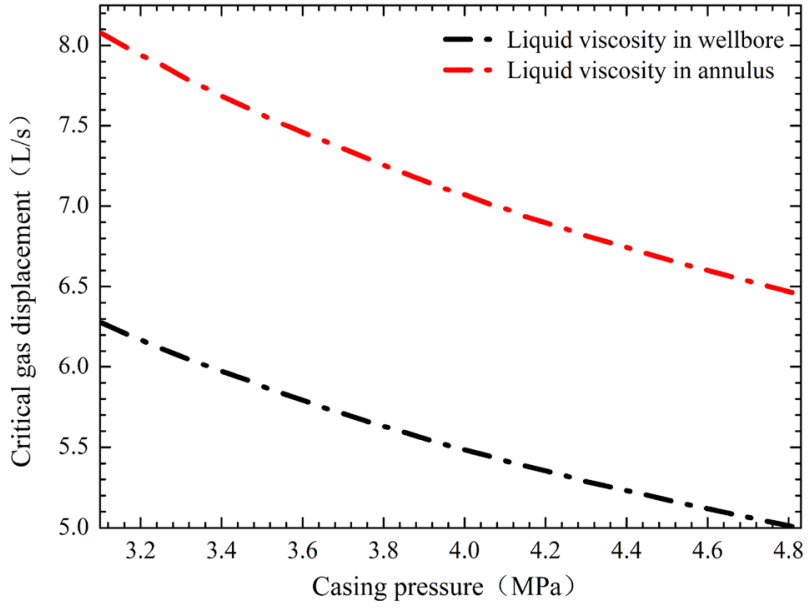

(b) The influence of casing pressure on gas displacement

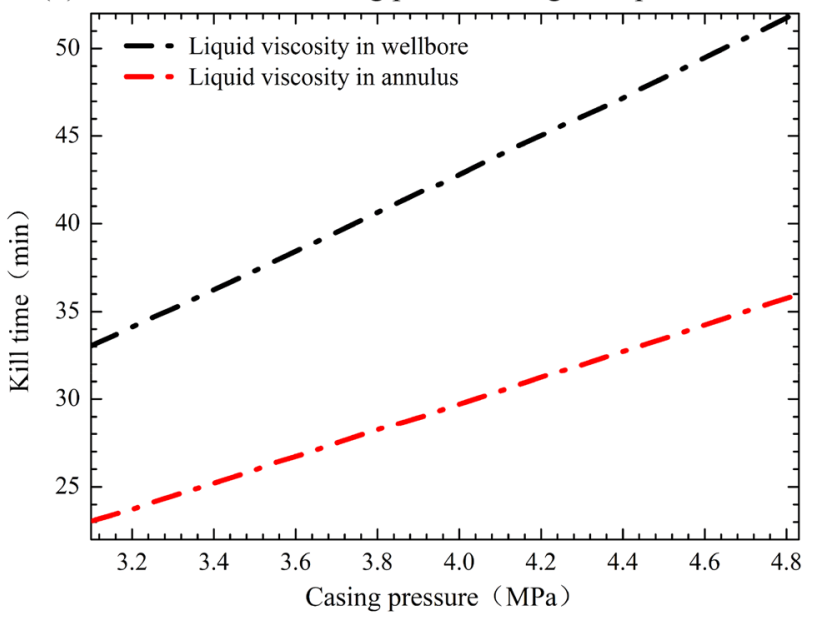

(c) The influence of casing pressure on kill time

Fig. 18 The influence of casing pressure on kill fluid displacement, gas displacement, and kill time consistent with the experimental results of Ramtahal. The drill pipe has an obstructive effect on flooding, mainly because the drill pipe plays a role in the diversion. Even if there are interface fluctuations in the gas-liquid flow, due to the existence of the drill pipe, this kind of fluctuation cannot bridge the liquid film on one side to the liquid film on the other side smoothly, so that flooding is not easy to occur.

However, it can be seen from Fig. 22 that when the outer diameter of the drill pipe increases, the critical displacement of the kill fluid and the critical displacement of the gas curve move down, which is opposite to the trend of the critical gas-liquid critical velocity curve. This is because, when the inner diameter of the casing does not change and the outer diameter of the drill pipe increases, the cross-sectional area of the annulus decreases. At this time, the area of the flow area decreases, and the flow rate corresponding to the same speed also decreases (Fig. 23).

The calculation results of different drill pipe outer diameters in the annulus are shown in Table 13.

\section{The influence of drill pipe eccentricity in the annulus}

In this paper, the minimum eccentricity of the drill pipe is $0 \mathrm{~m}$, and the maximum eccentricity of the drill pipe is $0.0508 \mathrm{~m}$ for calculation and analysis.

As shown in Figs. 24, 25: As the eccentricity of the drill pipe increases, the critical displacement of gas and liquid decreases. When the drill pipe is eccentric, the distance between the drill rod and the casing is widened on one side and narrowed on the other side. On the side with a narrower spacing, liquid level fluctuations are more likely to occur and cause liquid film bridging. Simultaneously, the critical gas-liquid velocity required for flooding is reduced, and flooding is more likely to occur. As shown in Fig. 26, with the increase of drill pipe eccentricity, the critical displacement of gas and liquid decreases, and the killing time incr eases.

The calculation results under different well deviation angles in the annulus are shown in Table 14.

\section{The influence of drill pipe joints in the annulus}

The drill pipe joint is a component of the drill pipe, divided into a male joint and a female joint connected to the two ends of the drill pipe body. In order to enhance the connection strength of the joint, the wall thickness of the pipe body needs to be increased at the joint. According to the thickening method, it can be divided into inner thickening, 
Table 11 Calculation results under different casing pressures

\begin{tabular}{|c|c|c|c|c|c|c|}
\hline & Casing pressure $(\mathrm{MPa})$ & \multicolumn{2}{|c|}{$\begin{array}{l}\text { Critical velocity of kill fluid } \\
(\mathrm{m} / \mathrm{s})\end{array}$} & \multicolumn{2}{|c|}{$\begin{array}{l}\text { Critical displacement of kill fluid } \\
(\mathrm{L} / \mathrm{s})\end{array}$} & $\begin{array}{l}\text { Gas critical } \\
\text { velocity } \\
(\mathrm{m} / \mathrm{s})\end{array}$ \\
\hline \multirow[t]{3}{*}{ In wellbore } & 3.10 & 0.159 & & 2.893 & & 0.345 \\
\hline & 3.965 & 0.159 & & 2.885 & & 0.304 \\
\hline & 4.83 & 0.158 & & 2.872 & & 0.277 \\
\hline \multirow[t]{4}{*}{ In annulus } & 3.10 & 0.229 & & 3.693 & & 0.401 \\
\hline & 3.965 & 0.250 & & 6.617 & & 0.437 \\
\hline & 4.83 & 0.269 & & 10.493 & & 0.470 \\
\hline & Casing pressure (MPa) & $\begin{array}{l}\text { Gas critical displacement } \\
(\mathrm{L} / \mathrm{s})\end{array}$ & $\begin{array}{l}\text { Injec } \\
(\mathrm{min}\end{array}$ & time of $5 \mathrm{~m}^{3}$ kill fluid & $\begin{array}{l}\text { Casing pres } \\
\text { injection of } \\
(\mathrm{MPa})\end{array}$ & $\begin{array}{l}\text { ure after } \\
\mathrm{m}^{3} \text { kill fluid }\end{array}$ \\
\hline \multirow[t]{3}{*}{ In wellbore } & 3.10 & 6.266 & 28.8 & & 0.40 & \\
\hline & 3.965 & 5.516 & 28.8 & & 1.26 & \\
\hline & 4.83 & 5.021 & 29.0 & & 2.13 & \\
\hline \multirow[t]{4}{*}{ In annulus } & 3.10 & 8.058 & 22.4 & & 0.06 & \\
\hline & 3.965 & 7.093 & 22.4 & & 0.93 & \\
\hline & 4.83 & 6.457 & 22.5 & & 1.79 & \\
\hline & \multicolumn{4}{|c|}{ Casing pressure (MPa) } & \multicolumn{2}{|c|}{$\begin{array}{l}\text { Time required to reduce } \\
\text { casing pressure to } 0 \\
\text { (min) }\end{array}$} \\
\hline \multirow[t]{3}{*}{ In wellbore } & \multicolumn{3}{|c|}{3.10} & \multicolumn{3}{|c|}{33.04} \\
\hline & \multicolumn{3}{|c|}{3.965} & \multicolumn{3}{|c|}{42.36} \\
\hline & \multicolumn{3}{|c|}{4.83} & \multicolumn{3}{|c|}{51.85} \\
\hline \multirow[t]{3}{*}{ In annulus } & \multicolumn{3}{|c|}{8.058} & \multicolumn{3}{|c|}{22.82} \\
\hline & \multicolumn{3}{|c|}{7.093} & \multicolumn{3}{|c|}{29.26} \\
\hline & \multicolumn{3}{|c|}{6.457} & \multicolumn{3}{|c|}{35.82} \\
\hline
\end{tabular}

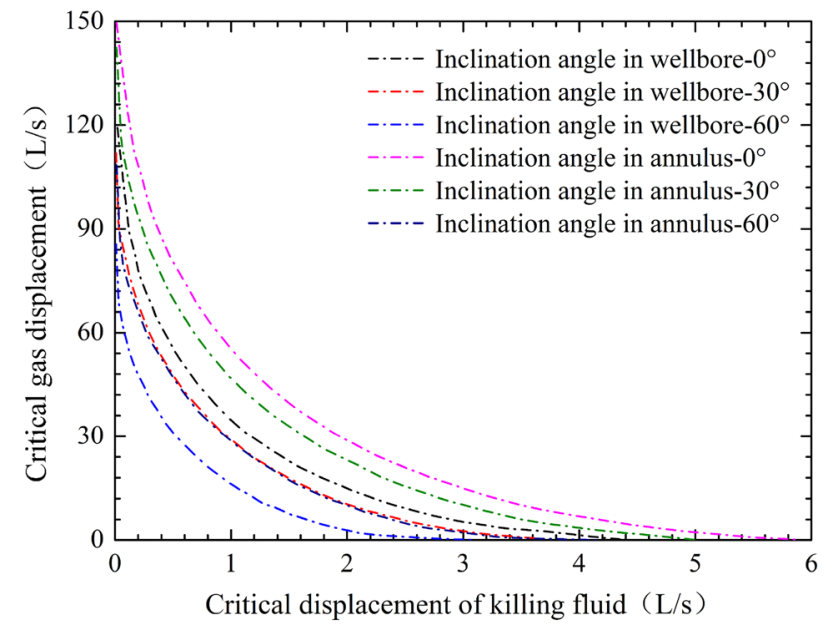

Fig. 19 The influence of well deviation angle on the critical displacement of flooding outer thickening, and inner and outer thickening. The internal thickening does not affect the outer diameter of the drill pipe. The inner thickening does not affect the outer diameter of the drill pipe, and the critical displacement of the flooding remains unchanged. In the case of outer thickening and inner and outer thickening, the outer diameter of the drill pipe changes, and the calculation is calculated by taking 1.1 times and 1.2 times the outer diameter length. The outer diameter is $0.0508 \mathrm{~m}$, the outer diameter of the drill pipe joint is $0.0559 \mathrm{~m}$ if 1.1 times and $0.0610 \mathrm{~m}$ if 1.2 times.

As shown in Fig. 27: When the outer diameter of the drill pipe joint increases, the flooding critical velocity increases, and the flooding critical velocity curve increases. This is the same as the influence trend of drill pipe outer diameter on 




(a) The influence of well inclination angle on kill fluid displacement

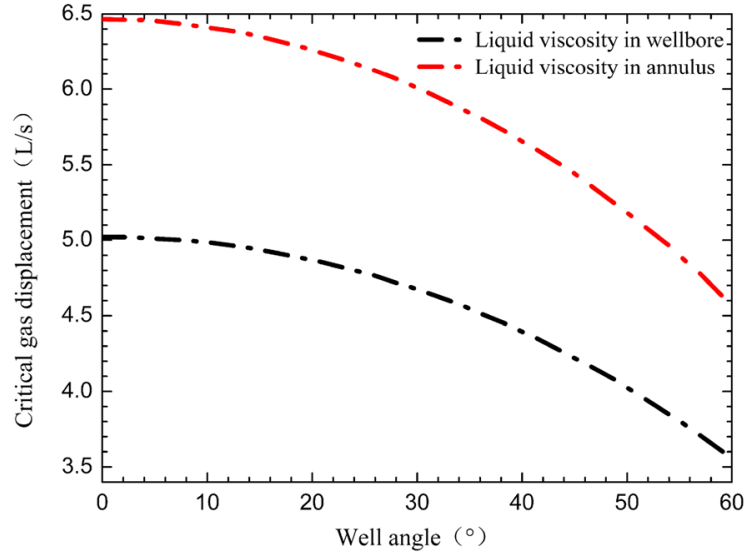

(b) The influence of well inclination angle on gas displacement

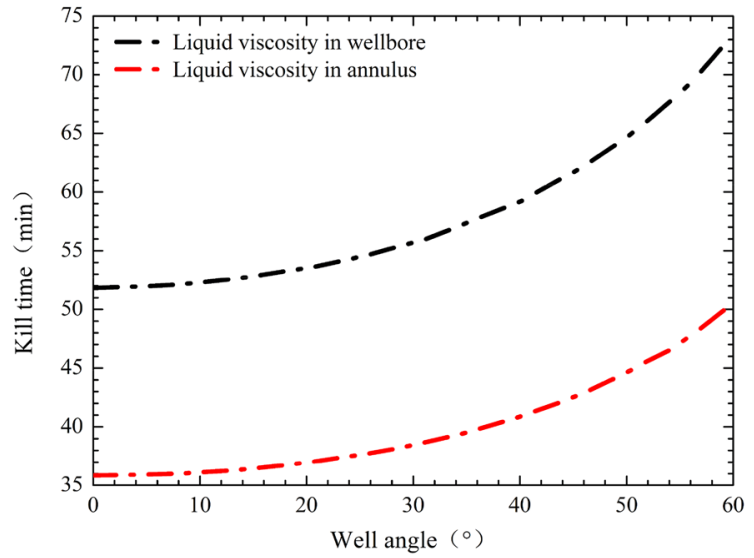

(c) The influence of well inclination angle on kill time

Fig. 20 The influence of well inclination angle on kill fluid displacement, gas displacement and kill time flooding critical velocity. It shows that at the drill pipe joint, due to the increase of wall thickness, the outer diameter of the joint increases, which plays a role in the drainage of kill fluid, so it is not easy to flooding.

As shown in Fig. 28: The critical flooding displacement decreases, and the flooding critical displacement curve moves down. This is because the flow area has a great impact on the flooding displacement.

The calculation results of different drill pipe joint outer diameters in the annulus are shown in Table 15.

When the outer diameter of the drill pipe joint increases, the critical speed of the flooding increases, but the critical displacement of the flooding decreases, and the critical displacement of the kill fluid and the critical displacement of the gas both decrease. This shows that flooding is less likely to occur when the drill pipe joint is thickened. However, due to the reduction in the area of the flow area and the reduction of the critical displacement, the outer diameter of the thickened drill pipe joint should still be used in the engineering calculation to select the displacement to avoid flooding (Fig. 29).

\section{Influence law}

Through calculation and analysis of physical and engineering parameters related to flooding. The effects of liquid viscosity $(\mu)$, liquid surface tension $(\sigma)$, gas density $\left(\rho_{\mathrm{g}}\right)$, killing fluid density $\left(\rho_{1}\right)$, casing inner diameter $\left(D_{1}\right)$, casing pressure $(p)$, well deviation angle $(\alpha)$, casing outer diameter $\left(D_{2}\right)$, drill pipe eccentricity $(e)$, and drill pipe joint outer diameter $(d)$ on flooding critical gas-liquid velocity and flooding critical gas-liquid displacement are obtained. As shown in Table 16.

By comparison, the hydrodynamic viscosity, liquid surface tension, gas density in the well, killing fluid density, casing inner diameter, casing pressure, and inclination angle have the same influence rules in the annulus and wellbore. In the annulus, the outer diameter of the drill pipe increases, the critical gas-liquid velocity increases, and the critical gas-liquid displacement decrease. 
Table 12 Calculation results under different well deviation angles

\begin{tabular}{|c|c|c|c|c|c|c|}
\hline & Well deviation angle $\left(^{\circ}\right)$ & \multicolumn{2}{|c|}{$\begin{array}{l}\text { Critical velocity of kill fluid } \\
(\mathrm{m} / \mathrm{s})\end{array}$} & \multicolumn{2}{|c|}{$\begin{array}{l}\text { Critical displacement of kill fluid } \\
(\mathrm{L} / \mathrm{s})\end{array}$} & $\begin{array}{l}\text { Gas critical } \\
\text { velocity } \\
(\mathrm{m} / \mathrm{s})\end{array}$ \\
\hline \multirow[t]{3}{*}{ In wellbore } & 0 & \multicolumn{2}{|l|}{0.158} & \multicolumn{2}{|l|}{2.872} & 0.277 \\
\hline & 30 & \multicolumn{2}{|l|}{0.147} & \multicolumn{2}{|l|}{2.673} & 0.258 \\
\hline & 60 & \multicolumn{2}{|l|}{0.112} & \multicolumn{2}{|l|}{2.031} & 0.196 \\
\hline \multirow[t]{4}{*}{ In annulus } & 0 & \multicolumn{2}{|l|}{0.229} & \multicolumn{2}{|l|}{3.693} & 0.401 \\
\hline & 30 & \multicolumn{2}{|l|}{0.213} & \multicolumn{2}{|l|}{3.437} & 0.373 \\
\hline & 60 & 0.162 & & \multicolumn{2}{|l|}{2.611} & 0.283 \\
\hline & Well deviation angle $\left(^{\circ}\right)$ & $\begin{array}{l}\text { Gas critical displacement } \\
(\mathrm{L} / \mathrm{s})\end{array}$ & \multicolumn{2}{|c|}{$\begin{array}{l}\text { Injection time of } 5 \mathrm{~m}^{3} \text { kill fluid } \\
(\mathrm{min})\end{array}$} & \multicolumn{2}{|c|}{$\begin{array}{l}\text { Casing pressure after } \\
\text { injection of } 5 \mathrm{~m}^{3} \text { kill fluid } \\
(\mathrm{MPa})\end{array}$} \\
\hline \multirow[t]{3}{*}{ In wellbore } & 0 & 5.021 & \multicolumn{2}{|c|}{29.02} & \multicolumn{2}{|l|}{2.13} \\
\hline & 30 & 4.673 & \multicolumn{2}{|c|}{31.18} & \multicolumn{2}{|l|}{2.13} \\
\hline & 60 & 3.551 & 41.04 & & 2.13 & \\
\hline In annulus & 0 & 6.457 & 22.56 & & 1.79 & \\
\hline & 30 & 6.009 & 24.25 & & 1.79 & \\
\hline & 60 & 4.566 & 31.91 & & 1.79 & \\
\hline & & Well deviation angle & & & $\begin{array}{l}\text { Time req } \\
\text { casing pr } \\
(\mathrm{min})\end{array}$ & $\begin{array}{l}\text { ed to reduce } \\
\text { sure to } 0\end{array}$ \\
\hline In wellbore & & 0 & & & 51.85 & \\
\hline & & 30 & & & 55.72 & \\
\hline & & 60 & & & 73.33 & \\
\hline In annulus & & 0 & & & 35.81 & \\
\hline & & 30 & & & 38.49 & \\
\hline & & 60 & & & 50.65 & \\
\hline
\end{tabular}

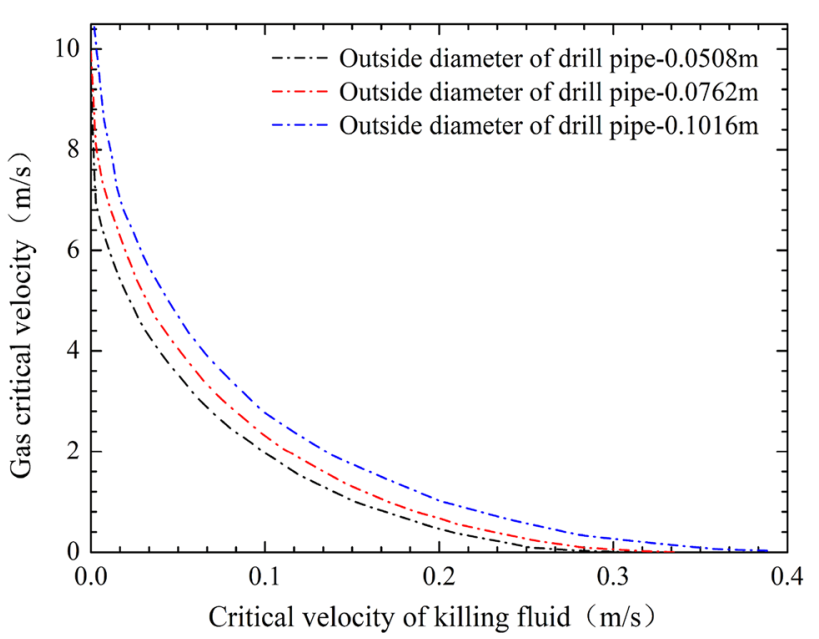

Fig. 21 Critical velocities under different drill pipe outer diameters

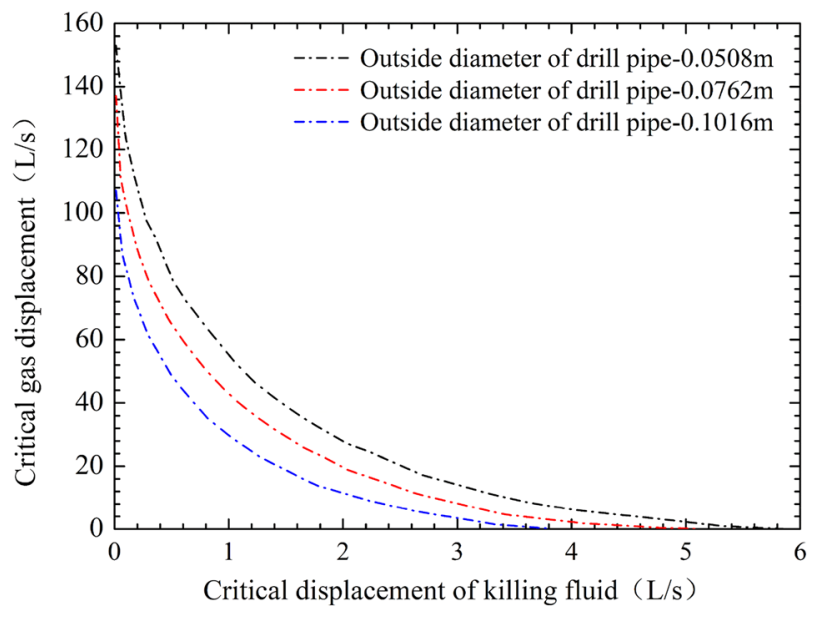

Fig. 22 Critical displacement under different drill pipe outer diameters 


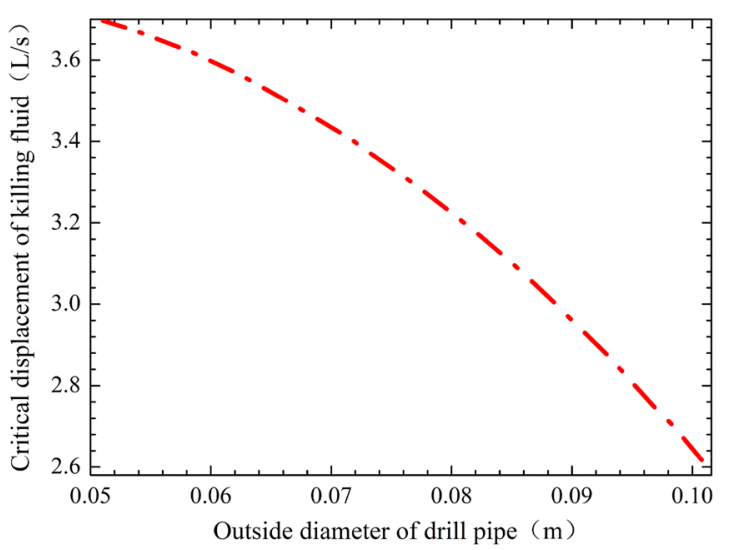

(a) The influence of drill pipe outer diameter on kill fluid displacement

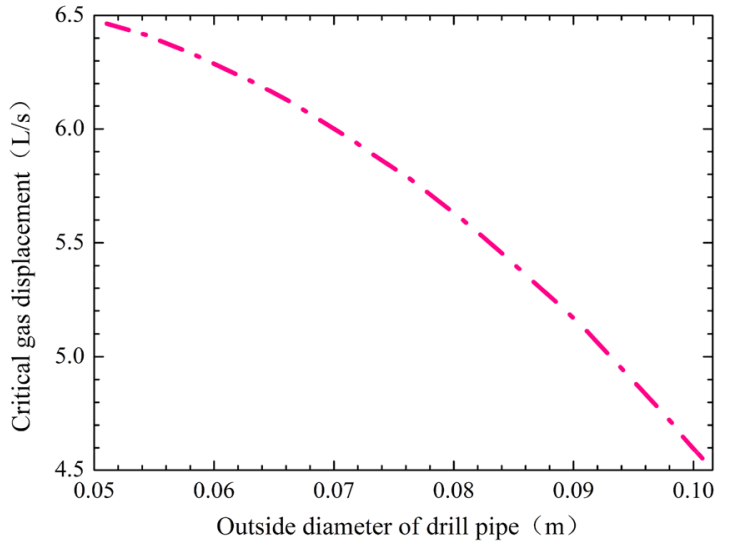

(b) The influence of drill pipe outer diameter on gas displacement

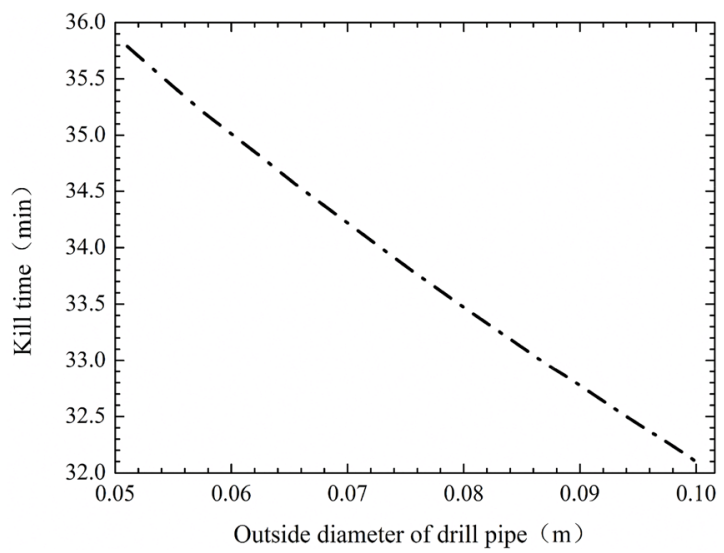

(c) The influence of drill pipe outer diameter on kill time

Fig. 23 The influence of drill pipe outer diameter on kill fluid displacement, gas displacement, and kill time

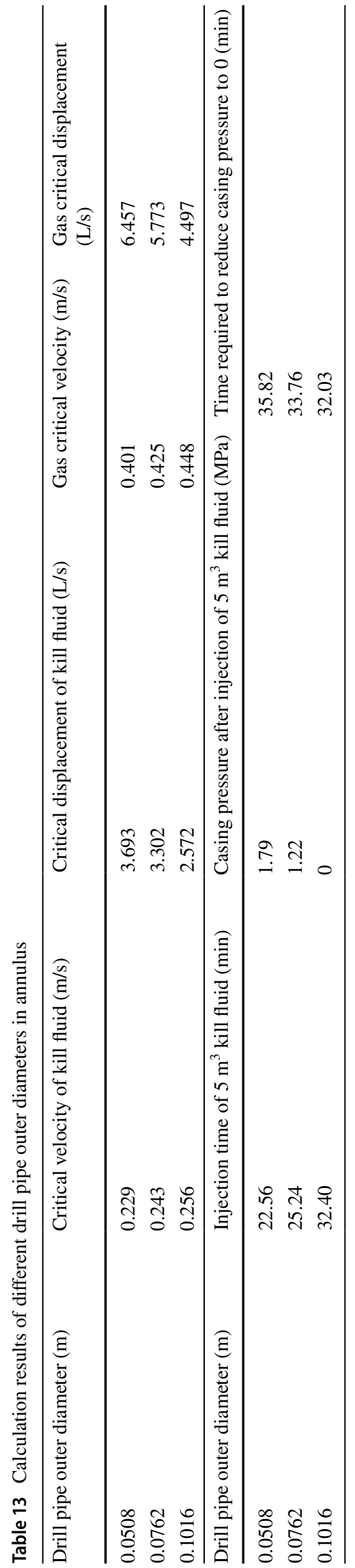




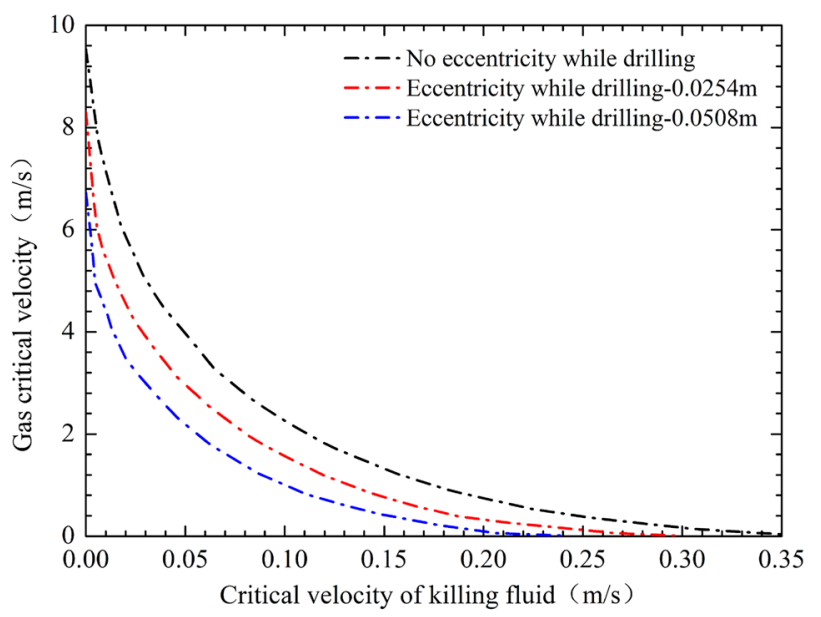

Fig. 24 The influence of drill pipe eccentricity on critical speed

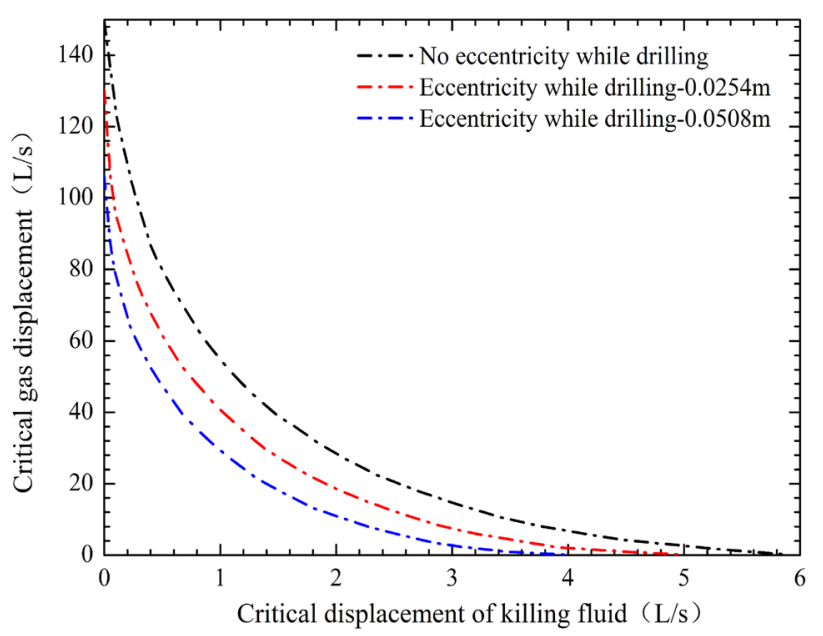

Fig. 25 The influence of drill pipe eccentricity on critical displacement



(a) The influence of drill pipe eccentricity on kill fluid displacement

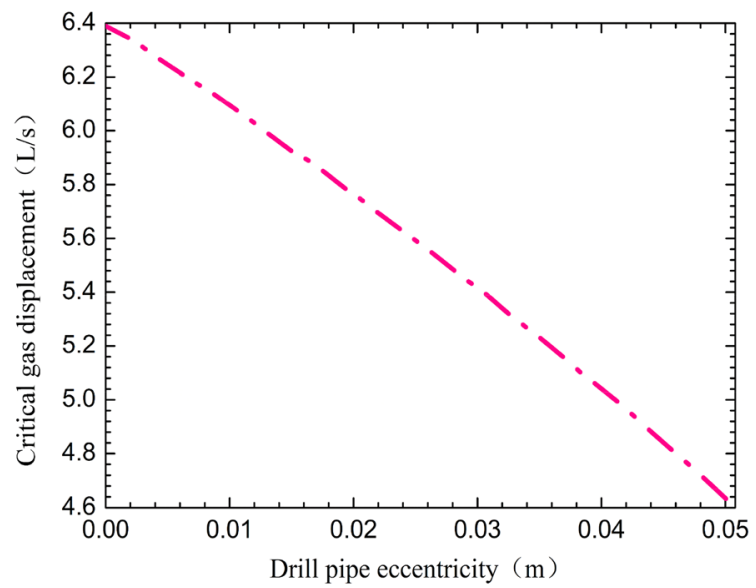

(b) The influence of drill pipe eccentricity on gas displacement

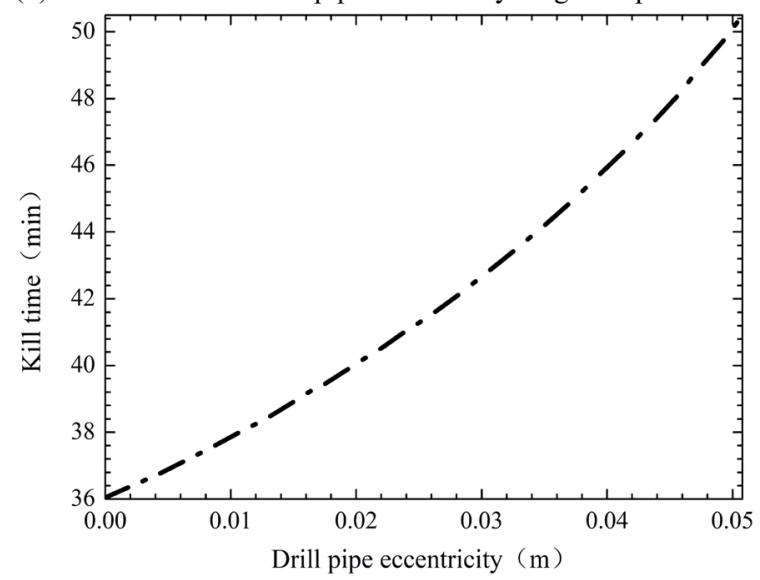

(c) The influence of drill pipe eccentricity on kill time

Fig. 26 The influence of drill pipe eccentricity on kill fluid displacement, gas displacement, and kill time 
Table 14 Calculation results under different well deviation angles in annulus

\begin{tabular}{|c|c|c|c|c|c|}
\hline \multirow{2}{*}{$\begin{array}{l}\text { Drill pipe eccentricity (m) } \\
0\end{array}$} & \multirow{2}{*}{$\begin{array}{l}\text { Critical velocity of kill fluid } \\
(\mathrm{m} / \mathrm{s})\end{array}$} & $\begin{array}{l}\text { Critical displacement of kill fluid } \\
(\mathrm{L} / \mathrm{s})\end{array}$ & \multicolumn{2}{|c|}{ Gas critical velocity $(\mathrm{m} / \mathrm{s})$} & \multirow{2}{*}{$\begin{array}{l}\text { Gas critical } \\
\text { displacement } \\
(\mathrm{L} / \mathrm{s})\end{array}$} \\
\hline & & 3.693 & 0.401 & & \\
\hline 0.0254 & 0.198 & 3.197 & 0.347 & & 5.590 \\
\hline 0.0508 & 0.162 & 2.609 & 0.283 & & 4.561 \\
\hline Drill pipe eccentricity (m) & $\begin{array}{l}\text { Injection time of } 5 \mathrm{~m}^{3} \text { kill fluid } \\
\text { (min) }\end{array}$ & \multicolumn{2}{|c|}{$\begin{array}{l}\text { Casing pressure after injection of } 5 \mathrm{~m}^{3} \text { kill } \\
\text { fluid }(\mathrm{MPa})\end{array}$} & \multicolumn{2}{|c|}{$\begin{array}{l}\text { Time required to reduce } \\
\text { casing pressure to } 0 \\
\text { (min) }\end{array}$} \\
\hline 0 & 22.56 & 1.79 & & 35.82 & \\
\hline 0.0254 & 26.06 & 1.79 & & 41.37 & \\
\hline 0.0508 & 31.94 & 1.79 & & 50.70 & \\
\hline
\end{tabular}

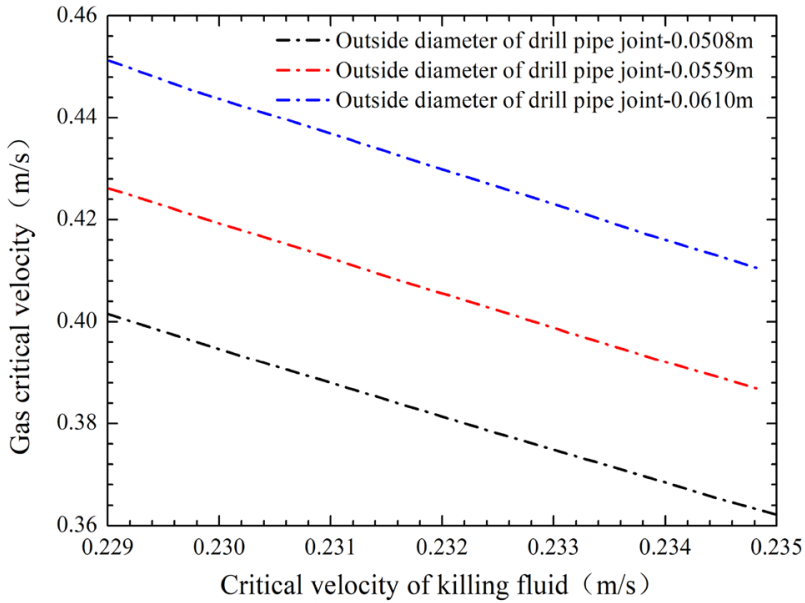

Fig. 27 The influence of the outer diameter of the drill pipe joint on the critical speed

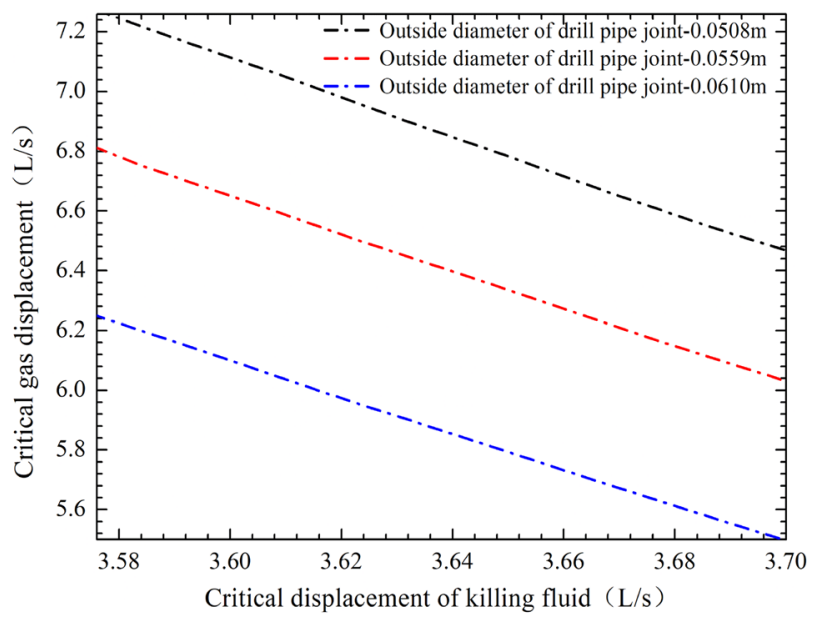

Fig. 28 The influence of the outer diameter of the drill pipe joint on the critical displacement

Table 15 Calculation results under different outside diameters of drill pipe joints in annulus

\begin{tabular}{|c|c|c|c|c|c|c|}
\hline \multirow{2}{*}{$\begin{array}{l}\text { Outside diameter of drill pipe } \\
\text { joint (m) } \\
0.0508\end{array}$} & \multirow{2}{*}{$\begin{array}{l}\text { Critical velocity of kill fluid } \\
(\mathrm{m} / \mathrm{s})\end{array}$} & \multicolumn{2}{|c|}{$\begin{array}{l}\text { Critical displacement of kill } \\
\text { fluid }(\mathrm{L} / \mathrm{s})\end{array}$} & \multicolumn{2}{|c|}{ Gas critical velocity $(\mathrm{m} / \mathrm{s})$} & \multirow{2}{*}{$\begin{array}{l}\text { Gas critical } \\
\text { displacement } \\
(\mathrm{L} / \mathrm{s})\end{array}$} \\
\hline & & 3.693 & & 0.401 & & \\
\hline 0.0559 & 0.232 & 3.640 & & 0.406 & & 6.364 \\
\hline 0.0610 & 0.235 & 3.575 & & 0.411 & & 6.250 \\
\hline $\begin{array}{l}\text { Outside diameter of drill pipe joint } \\
(\mathrm{m})\end{array}$ & \multicolumn{2}{|c|}{$\begin{array}{l}\text { Injection time of } 5 \mathrm{~m}^{3} \text { kill fluid } \\
(\mathrm{min})\end{array}$} & \multicolumn{2}{|c|}{$\begin{array}{l}\text { Casing pressure after injection of } 5 \mathrm{~m}^{3} \text { kill } \\
\text { fluid (MPa) }\end{array}$} & \multicolumn{2}{|c|}{$\begin{array}{l}\text { Time required to reduce } \\
\text { casing pressure to } 0 \\
\text { (min) }\end{array}$} \\
\hline 0.0508 & 22.56 & \multicolumn{2}{|r|}{1.79} & \multicolumn{3}{|c|}{35.82} \\
\hline 0.0559 & 22.89 & \multicolumn{2}{|r|}{1.79} & \multicolumn{3}{|c|}{36.42} \\
\hline 0.0610 & \multicolumn{2}{|l|}{23.31} & 1.79 & \multicolumn{3}{|c|}{37.19} \\
\hline
\end{tabular}




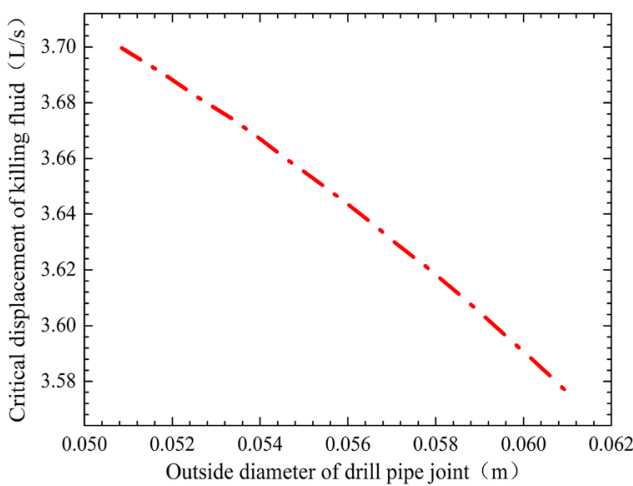

(a) The influence of the drill pipe joint outer diameter on kill fluid displacement



(b) The influence of the drill pipe joint outer diameter on gas displacement

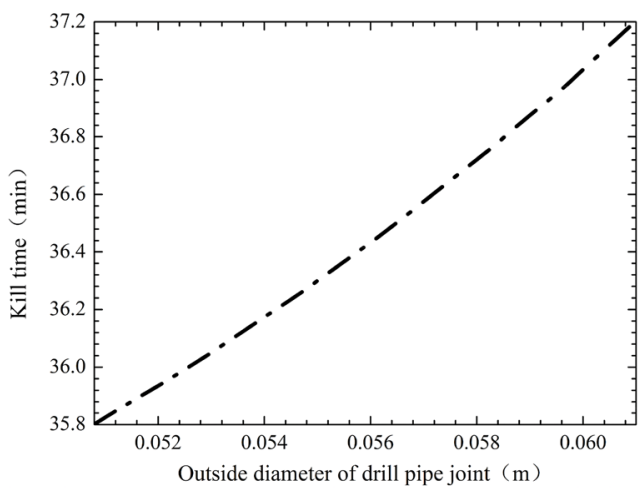

(c) The influence of the drill pipe joint outer diameter on kill time

Fig. 29 The influence of the drill pipe joint outer diameter on kill fluid displacement, gas displacement, and kill time

\section{Conclusion}

(1) In the field of empty well killing, flooding mainly exists in dynamic displacement killing because in the working condition of dynamic displacement killing gas and liquid simultaneously, there is gas-liquid countercurrent contact, which forms the necessary condition for flooding to occur. The related parameters that cause flooding include physical property parameters and engineering parameters. Physical property parameters include hydrodynamic viscosity, liquid surface tension, and gas density in the well. Engineering parameters include killing fluid density, casing inner diameter, drill pipe outer diameter, casing pressure, inclination angle, drill pipe joint diameter, and drill pipe eccentricity.

(2) When the values of hydrodynamic viscosity, gas density in the well, shut-in casing pressure, inclination angle, drill pipe outer diameter, drill pipe joint outer diameter, and drill pipe eccentricity increase, flooding is more likely to occur, and they are more likely to cause flooding. Thus, it has a promoting effect, and the critical displacement of flooding decreases with the increase of these parameters; when the values of liquid surface tension, killing fluid density and casing inner diameter increase, flooding is more difficult to occur, and they hinder the occurrence of flooding Function, the critical displacement of flooding increases with the increase of these parameters.

(3) Based on the safety point of view, the critical gas-liquid velocity is calculated by taking the gas density in the well at the initial time of well killing, and the influence of density on the critical gas-liquid velocity and critical gas-liquid displacement is studied. The follow-up scholars can consider the dynamic displacement killing research of the whole process dynamic gas-liquid displacement.
Table 16 Changes in critical velocity, critical displacement, and kill time when the related parameters of flooding increase

\begin{tabular}{llllllllllll}
\hline Flooding parameters & $\mu$ & $\sigma$ & $\rho_{\mathrm{g}}$ & $\rho_{1}$ & $D_{1}$ & $p$ & $\alpha$ & $D_{2}$ & $e$ & $d$ & \\
\hline Critical velocity of kill fluid (m/s) & Wellbore & $\downarrow$ & $\uparrow$ & $\downarrow$ & $\uparrow$ & $\uparrow$ & $\downarrow$ & $\downarrow$ & $\backslash$ & $\backslash$ & $\backslash$ \\
& Annulus & $\downarrow$ & $\uparrow$ & $\downarrow$ & $\uparrow$ & $\uparrow$ & $\downarrow$ & $\downarrow$ & $\uparrow$ & $\downarrow$ & $\uparrow$ \\
Gas critical velocity (m/s) & Wellbore & $\downarrow$ & $\uparrow$ & $\downarrow$ & $\uparrow$ & $\uparrow$ & $\downarrow$ & $\downarrow$ & $\backslash$ & $\backslash$ & $\backslash$ \\
Critical displacement of kill fluid (L/s) & Wellbore & $\downarrow$ & $\uparrow$ & $\downarrow$ & $\uparrow$ & $\uparrow$ & $\downarrow$ & $\downarrow$ & $\backslash$ & $\backslash$ & $\backslash$ \\
& Annulus & $\downarrow$ & $\uparrow$ & $\downarrow$ & $\uparrow$ & $\uparrow$ & $\downarrow$ & $\downarrow$ & $\downarrow$ & $\downarrow$ & $\downarrow$ \\
Critical gas displacement (L/s) & Wellbore & $\downarrow$ & $\uparrow$ & $\downarrow$ & $\uparrow$ & $\uparrow$ & $\downarrow$ & $\downarrow$ & $\backslash$ & $\backslash$ & $\backslash$ \\
& Annulus & $\downarrow$ & $\uparrow$ & $\downarrow$ & $\uparrow$ & $\uparrow$ & $\downarrow$ & $\downarrow$ & $\downarrow$ & $\downarrow$ & $\downarrow$ \\
Kill time (min) & Wellbore & $\uparrow$ & $\downarrow$ & $\uparrow$ & $\downarrow$ & $\downarrow$ & $\uparrow$ & $\uparrow$ & $\backslash$ & $\backslash$ & $\backslash$ \\
& Annulus & $\uparrow$ & $\downarrow$ & $\uparrow$ & $\downarrow$ & $\downarrow$ & $\uparrow$ & $\uparrow$ & $\downarrow$ & $\uparrow$ & $\uparrow$ \\
\hline
\end{tabular}


Funding The authors thank the financial supports from the National Natural Science Foundation of China (No. 51274168), the National Key R\&D Program of China (No. 2018YFC0310202), and the Southwest Petroleum University Graduate Research and Innovation Fund Key Program (No. 2020CXZD30).

\section{Declarations}

Conflicts of interest The authors declare that they have no known competing financial interests or personal relationships that could have influenced the work reported in this paper.

Open Access This article is licensed under a Creative Commons Attribution 4.0 International License, which permits use, sharing, adaptation, distribution and reproduction in any medium or format, as long as you give appropriate credit to the original author(s) and the source, provide a link to the Creative Commons licence, and indicate if changes were made. The images or other third party material in this article are included in the article's Creative Commons licence, unless indicated otherwise in a credit line to the material. If material is not included in the article's Creative Commons licence and your intended use is not permitted by statutory regulation or exceeds the permitted use, you will need to obtain permission directly from the copyright holder. To view a copy of this licence, visit http://creativecommons. org/licenses/by/4.0/.

\section{References}

Andersen PS, Wurtz J (1981) Adiabatic steam-water annular flow in an annular geometry. Multiph Flow 7(2):235-239

Brauner N, Barnea D (1986) Slug/Churn transition in upward gasliquid flow. Chem Eng Sci 41(1):159-163

Caetano EF, Shoham O, Brill JP (1992) Upward vertical two-phase flow through an annulus. J Energy Res Technol 114(1):1-13

Carlos OV, Humberto CM, Victor VA (2001) Successful well control in the Cantarell Field applying the dynamic method. SPE71372

Chung KS, Liu CP, Tien CL (1980) Flooding in two-phase counter current flows II experimental investigation. Physicochem Hydrodyn 209-220

Clift R, Pritchard CL, Nedderman RM (1966) The effect of viscosity on the flooding conditions in wetted wall columns. Chem Eng Sci 21(1):87-95
Flores-Avila FS, Smith JR, Bourgoyne Jr AT (2002) Experimental evaluation of control fluid fallback during off-bottom well control: effect ofdeviation angle. SPE74568

Gong PB, Sun BJ, Wang ZY et al (2012) Study on killing method under the condition of air injection in well. J Pet Nat Gas 34(1):100-103

Grace RD (1994) Advanced blow out \& well control. Gulf Publishing Co, Houwton

Hasan AR, Kabir CS (1992) Two-phase flow in vertical and inclined annuli. Multiph Flow 18(2):279-293

Kelessidis VC, Dukler AE (1989) Modeling flow pattern transitions for upward gas-liquid flow in vertical concentric and eccentric annuli. Multiph Flow 15(2):173-191

Kutateladze SS (1972) Elements of the hydrodynamics of gas-liquid systems. Fluid Mech Sov Res 14:29-50

Levy S (1999) Two-Phase flow in complex systems. Wiley-Interscience, New York

Li H, Sun BJ (2009) Prediction of wellbore temperature field in high pressure gas well killing and analysis of influencing factors. $J$ China Univ Pet 33(6):61-65

Li Q, Yang XL, Wu XZ (2013) Control method of bottom hole pressure in well killing process. Nat Gas Ind 33(9):87-90

Mouza AA, Pantzali MN, Paras SV (2005) Falling film and flooding phenomena in small diameter vertical tubes: the influence of liquid properties. Chem Eng Sci 60(18):4981-4991

Ren MP, Li XF, Li YY (2014) Calculation of killing parameters of dynamic displacement method. J Pet 35(2):366-370

Stadatomi M, Sato Y (1982) Two-phase flow in vertical noncircular channels. Multiph Flow 8(6):641-655

Taitel Y, Barnea D, Dukler AE (1980) Modeling flow pattern transition for steady upward gas-liquid flow in vertical tubes. AICHE J1(26):345-354

Tao XL, Xu H, Mu YJ (2014) Application of unconventional well killing technology. Fault Block Oil Gas Field 21(2):252-255

Vijayan M, Jayamti S, Balakrishnan AR (2000) Effect of tube diameter on flooding. Int J Multiph Flow 27(5):797-816

Wei N, Meng YF, Wu PC et al (2017) Mathematical model of gasliquid two-phase transient flow in empty well killing wellbore of gas drilling. Nat Gas Ind 37(6):64-71

Yang XL, Li Q, Yuan BF (2013) Evaluation of safety drilling control parameters for underbalanced drilling. Fault Block Oil Gas Field 20(5):671-673

Zapke A, Kroger DG (2000) Countercurrent gas-liquid flow in inclined and vertical ducts: the validity of the Froude-Ohnesorge number correlation for flooding. Int J Multiph Flow 26(9):1457-1468 